\title{
Difficult Conversations
}

\author{
The Dynamics Surrounding New Zealand Women's \\ Disclosure of Intimate Partner Violence to Family and \\ Friends
}

By Jared Reid Walton

A thesis submitted to Victoria University of Wellington in fulfilment of the requirements for the degree of Master of Arts in Criminology

Victoria University of Wellington

May 2012 


\begin{abstract}
One in three New Zealand women has experienced Intimate Partner Violence (IPV) at some stage in their lives, with the vast majority of these women disclosing to a family member or friend at some stage during or after the relationship. Therefore, it is important to understand the dynamics involved with this disclosure. This study draws on feminist perspectives and a grounded theory methodology to examine six women's experiences with these dynamics. These women reported being very careful about when they disclosed, often going to great lengths to hide the abuse, and who they disclosed to. Furthermore, they explained that they felt a number of barriers to disclosure, both of a personal and social nature. They also described a number of different reactions they received, both negative and positive. In reflecting on their situations these women had come to a number of realisations, while during the interviews a number of observations were made, particularly regarding the strength they showed. In bringing their experiences together, it was clear that upon disclosure women require their family and friends to listen non-judgementally; help them to understand IPV; support the woman's decisions; and offer tangible support if necessary. However, negative experiences were not uncommon, and it was hypothesised that there are two forms of this: passive, which comes about through a lack of understanding; and active, which comes about through a conscious decision to be unsupportive. In concluding, it was suggested that widespread education be introduced, and public awareness campaigns be widened, to increase public understanding of IPV.
\end{abstract}




\section{Dedication and Acknowledgements}

First of all, I would like to dedicate this thesis to Kristy Kearney. Our many conversations about a variety of feminist issues played a significant role in my decision to do this research. It's a shame that you are not with us to see this thesis, and I hope that it is up to the standard that you would have expected.

I would like to thank the four informants and six participants who agreed to be interviewed by me for this research. The wealth of knowledge imparted on me by the informants was invaluable, and I do not know if I would have been able to get as far as I did without this. The strength and openness of the six women whose stories make up this thesis was a true inspiration. I cannot begin to imagine what you have been through, and your willingness to share your stories with me is something for which I am ever grateful.

To Women's Refuge, in particular Kiri Hannifin and Eleanor Butterworth, thank you for putting me in contact with the participants for this study. I could not have completed my research without this, and I really appreciate the efforts you made. I would also like to thank the others working in the field who helped me while I was preparing for this research, specifically Fleur McLaren and Sheryl Hann at the Ministry of Social Development.

To everyone in the School of Social and Cultural Studies, thank you for your friendly faces and supportive words over the last year. To everyone on the $9^{\text {th }}$ floor, thank you for your continued friendship and distractions throughout the course of my research. To all of my lecturers, in particular Charles Sedgwick, Lizzy Stanley and Jan Jordan, thank you for all of the advice and support throughout my years at university. Without you I would not have made it this far.

I was fortunate enough to have a number of people who were willing to proof read my thesis for me. Thank you to Tracey Vale, Samantha Keene, 
Cara Gledhill, Amanda Ward, Mariska Kecskemeti, Owen Hughes, Hollie Doar, Kim Dobson and Sonja Bohn for your efforts in this. Your offers of assistance in the final stages of the process meant a lot to me.

I have only managed to get this far with the support of many amazing friends. While it is difficult to name everyone, I would like to specifically thank Kellie Hoy, Kim Dobson, Hollie Doar, Sonja Bohn, Cara Gledhill, Samantha Keene, Cassie Callard, Emily Martin, Jess Robieson, Jack Thomson, Tom Corser, David Knight, Lotti O’Dea, Lara Bell, Marie Upton, Denny Anderson, Kristina Clayton, Shani Hay, Staci Jackson, Kapa Te Aho, Mariska Kecskemeti, Marty Kain, Gabrielle Podvoiskis, Nick James, Reese McKee and Samwell Warren. Without your support and patience I question whether I would have maintained my sanity for long enough to get anywhere near completion.

I am lucky to have a very supportive family behind me. Thank you to my extended family, especially my aunties and uncles, for leaving your doors open to me for as long as I can remember. Throughout the hectic five years that I've been at university this has provided me with a much needed sense of stability. To my immediate family - Dad, Daniel, Tess and Megumi you may be scattered around the globe but I always know that you are 100 per cent behind me in everything I do. Without your continuing love, I would not be where I am now.

Finally, I would like to acknowledge two very important women. The first is my mother, Sally. Not a day goes by when I do not think about you, and I hope that my completion of this thesis would have made you proud. The second is my amazing supervisor, Venezia Kingi. Throughout the past year you have been a mentor and a friend to me. Without the advice and support that you have given me, this thesis would never have got off the ground. I cannot thank you enough for everything that you have done. 


\section{Table of Contents}

Abstract

Dedication and Acknowledgements iii

Table of Contents $\quad$ v

1 Introduction $\quad 1$

Introduction

Defining IPV

The Prevalence of IPV 3

The Effects of IPV 3

Societal Norms Surrounding IPV 4

General IPV Help-Seeking $\quad 7$

The Importance of Informal Support 9

The Effectiveness of Informal Support 10

$\begin{array}{ll}\text { Summary } & 14\end{array}$

2 Methodology 17

$\begin{array}{ll}\text { Introduction } & 17\end{array}$

Theoretical Underpinnings 17

$\begin{array}{ll}\text { Research Design } & 21\end{array}$

3 Personal Factors - Actions and Thoughts 29

Introduction 29

Actions Taken to Manage the Situation 29

Reasons Not to Disclose 32

Reasons for Disclosure $\quad 37$

Summary 38 
4 Social Factors - Barriers, Reactions and Effects 42

Introduction 42

Social Barriers to Disclosure $\quad 42$

Negative Reactions $\quad 49$

Positive Reactions $\quad 60$

$\begin{array}{ll}\text { Summary } & 65\end{array}$

5 Recent factors - Ongoing Support, Reflections and Observations 72

$\begin{array}{ll}\text { Introduction } & 72\end{array}$

$\begin{array}{ll}\text { Ongoing Support } & 72\end{array}$

Reflections $\quad 75$

Observations $\quad 82$

$\begin{array}{ll}\text { Summary } & 84\end{array}$

6 Conclusions $\quad 87$

$\begin{array}{ll}\text { Introduction } & 87\end{array}$

Summary of Findings $\quad 87$

Overall Findings $\quad 89$

Concluding Remarks 95

$\begin{array}{ll}\text { References } & 97\end{array}$

Appendix A: Ethics Approval 105

Appendix B: Informant Information Sheet and Consent Form 106

Appendix C: Informant Interview Guide 108

Appendix D: Participant Information Sheet and Consent Form 109

Appendix E: Participant Interview Guides $\quad 111$ 


\section{Chapter 1: Introduction}

\section{Introduction}

This research aims to examine the dynamics involved in survivors' disclosure of intimate partner violence (IPV) to family and friends. Using data obtained from interviews with women who have experienced IPV, this study attempts to give these women a voice in order to effect change in areas they identified as problematic. The first chapter provides a review of the literature, which will start with the formulation of a working definition of IPV and an examination of its prevalence, both in New Zealand and internationally. From there the effects of IPV on those who experience it will be assessed, followed by a discussion of the societal norms surrounding IPV. This will be succeeded by a consideration of the help-seeking behaviours of those who experience IPV and an exploration of the importance of informal help-seeking. This review will conclude with an inquiry into the effectiveness of informal support, and specific factors that determine if informal support is effective or not. In many places throughout this thesis, sexual violence will also be referred to due to the similarities between society's treatment of survivors of sexual abuse and the associated effects it has on them.

\section{Defining IPV}

There is no single definition of IPV. In order to conduct research into the area, the definition used needs to be "meaningful in social terms but [also] manageable in research terms” (Leibrich, Paulin, \& Ransom, 1995, p. 31). This is difficult as there are a number of competing definitions of IPV, which can alter the focus and outcome of a study significantly (Hayden, 2010; M. P. Johnson, 1995; Leibrich, et al., 1995). For instance, Michael Johnson (1995) noted that there were two major factions within the IPV literature - the family violence perspective, which argues that both genders perpetrate violence equally; and the feminist perspective, which states that the vast majority of IPV is perpetrated by males against females. Johnson (1995) states that the two perspectives focus on different types of violence, 
with the family violence perspective focusing on common couple violence and the feminist perspective focusing on patriarchal terrorism. He states that common couple violence is the most prevalent type of IPV, and involves both partners engaging in minor violent behaviours at a low frequency with little chance of injury or significant escalation (Carlson, 1997; Hayden, 2010; M. P. Johnson, 1995). On the other hand, patriarchal terrorism is a more severe form of violence committed mostly by males against their female intimate partners in a wider context of abusive and controlling behaviours. This violence is more likely to escalate to a fatal level and is often more frequent (M. P. Johnson, 1995). The discrepancy between the two perspectives is the result of differences in the definitions. Common couple violence is found when a study focuses purely on 'violent acts' and patriarchal terrorism is found when a study focuses on a wider range of behaviours (Hayden, 2010). From this stage onwards, I will use IPV to describe patriarchal terrorism, due to its greater impact on those who experience it and on society more generally.

The behaviours involved in IPV often include physical abuse such as kicking, hitting or biting; emotional abuse such as name calling and attempts to belittle one's partner; sexual abuse, including marital rape; and attempts to use tactics of social and financial control (Denzin, 1984; I. M. Johnson, 2007; M. P. Johnson, 1995). These are often used in a "pattern of intimidation, coercive control, and oppression" (Dasgupta, 2002 cited in Hayden, 2010, p. 5) in an attempt to invoke fear and intimidation, and to maintain control (M. P. Johnson, 1995; Leibrich, et al., 1995; Ministry of Social Development, 2002). These behaviours can take place in a marriage, co-habiting relationship or another form of relationship "where significant others are not part of the physical household but are part of the family and/or are fulfilling the function of family" (Ministry of Social Development, 2002, p. 8). Taking these factors into account, the definition of IPV for the purposes of this study is 'any situation where a male engages in behaviours of a physical, verbal or psychological nature, directed towards 
his female spouse or other intimate partner, in an attempt to cause physical or emotional harm AND maintain power and control over her'. Sexual abuse has been omitted from this definition due to its sensitive nature, while female-perpetrated and same-sex IPV have been excluded due to the interest in the patriarchal nature of the power and control aspects.

\section{The Prevalence of IPV}

International estimates of the prevalence of IPV range between 10 and 70 per cent of women, depending on the method of the study and the country in which it is conducted, with most estimates sitting around one third to one half (Fanslow \& Robinson, 2004; Fanslow \& Robinson, 2010; GarciaMoreno, Jansen, Ellsberg, Heise, \& Watts, 2006; I. M. Johnson, 2007; Leibrich, et al., 1995; Van Hook, 2000; West \& Wandrei, 2002). In New Zealand, IPV is seen as an important social issue (Giles, Curreen, \& Adamson, 2005), with Metzger and Woodley (2010, p. 6) stating that one in three women has experienced IPV in their lifetime and 56 women were killed by a member of their family between the years 2000 and 2004 (See also: Fanslow \& Robinson, 2004; Leibrich, et al., 1995).

\section{The Effects of IPV}

IPV has a range of detrimental effects on those who experience it. Not only can IPV have a negative impact on a woman's physical health, including sexual and reproductive health (Fanslow \& Robinson, 2004; Fanslow, Robinson, Crengle, \& Perese, 2010; Garcia-Moreno, et al., 2006; Hayden, 2010; Kearney, 2001; Towns \& Adams, 2009); but also on their mental and emotional health (Davis \& Brickman, 1996; Fanslow, et al., 2010; GarciaMoreno, et al., 2006; Hayden, 2010; Kaniasty \& Norris, 1992; Kearney, 2001; Van Hook, 2000). Effects on the mental health of women who experience IPV include greater risk of depression; anxiety; substance abuse; and suicidal thoughts, as well as increased feelings of fear; hostility; helplessness; and loss of control (Davis \& Brickman, 1996; Hayden, 2010; Kaniasty \& Norris, 1992; Kearney, 2001; Van Hook, 2000). Furthermore, 
IPV can cause survivors to experience significant financial loss (Kearney, 2001) and extreme isolation (Giles, et al., 2005; Kearney, 2001; Waldrop \& Resick, 2004). As such, IPV can be very debilitating for anyone who experiences it.

\section{Societal Norms Surrounding IPV}

IPV is influenced by a number of social factors; chief amongst these is a system of patriarchal gender relations. The way in which society is structured provides men with a disproportionate amount of financial, social and cultural power within a relationship (Denzin, 1984; Hayden, 2010; M. P. Johnson, 1995; McLaren, 2010; Towns \& Adams, 2009). This is partially due to the gendered division of labour, in which men are more likely to hold higher-paying jobs while women are more likely to engage in unpaid work, such as house-cleaning and child-rearing (Bui, 2003; Denzin, 1984). This has the effect of placing women in a position where they are seen as subordinate to their partner, while also limiting their influence in making decisions. This subordination and limitation of influence impacts on the overall nature of the relationship, giving males the balance of power and making it difficult for women to leave (Denzin, 1984; Towns \& Adams, 2009). However, women's experiences of gender inequality and IPV are not universal, as culture can play a significant role in this experience (Bui, 2003; Fanslow, et al., 2010; Hayden, 2010). For instance, cultures that place more value on male dominance have higher instances of IPV, as do cultures in which violence is more readily accepted (Hayden, 2010; Nayak, Byrne, Martin, \& Abraham, 2003).

Understanding of the issue of IPV in society is often influenced by the presence of societal myths (Aubrey \& Ewing, 1989; Pavlou \& Knowles, 2001; Towns \& Adams, 2009; West \& Wandrei, 2002). The most pervasive of these myths is that women's actions contribute to their victimisation. An illustration of this can be found in an Australian newspaper article in which a court magistrate is quoted as saying: “women cause a lot of problems by 
nagging, bitching and emotionally hurting men" (The Age, 31/09/99, quoted in Pavlou \& Knowles, 2001). In addition to the claim that women provoke men, there are also claims that women who stay in violent relationships are emotionally disturbed, are asking for the abuse and are masochistic (Aubrey \& Ewing, 1989; West \& Wandrei, 2002). Most women who experience IPV are viewed as having traditional family values, which cause them to be passive victims (Aubrey \& Ewing, 1989; Towns \& Adams, 2009; West \& Wandrei, 2002). Such myths have a significant impact on the actions of perpetrators, women who experience violence and, potentially, support people.

A major issue related to these myths is societal attitudes towards IPV. A number of New Zealand studies show that the majority of men and women state that IPV is not acceptable under any circumstance (Fanslow, et al., 2010; Leibrich, et al., 1995; McLaren, 2010). However, when presented with specific scenarios in which IPV may occur, a large proportion of people believe there are some situations (for instance, if a man finds his partner in bed with someone else) in which a man can be excused for hitting his partner (Leibrich, et al., 1995; McLaren, 2010). Furthermore, many New Zealanders think that violence towards women results from a loss of control; men's naturally aggressive tendencies; or a need to maintain their 'manhood', rather than through a desire to control their partner (Leibrich, et al., 1995; McLaren, 2010). The inaccuracy of these beliefs and the underlying acceptance of some instances of IPV are a cause for concern within New Zealand society.

Many people have a 'common sense' belief that anyone suffering the horrors of an abusive relationship should find it easy to leave, which influences their reactions to those involved (Taylor \& Sorenson, 2005; Towns \& Adams, 2009). However, this belief is inaccurate; a large number of factors influence a woman's ability and willingness to leave such a relationship. For instance, societal expectations have a significant influence 
on whether a woman will leave a violent relationship. These expectations place an emphasis on the nuclear family staying together, where possible, and place stigma upon single mothers, especially in communities which emphasise traditional religious values (Ferraro \& Johnson, 1983; Kearney, 2001; Towns \& Adams, 2009). As a result, women often stay in relationships for longer than they would otherwise as they feel a responsibility to make it work, especially when there are children involved.

The specific dynamics of each relationship can also have a major influence on women's responses. For instance, even in abusive relationships there are often feelings of love present between partners, especially if the violence is infrequent (Ferraro \& Johnson, 1983; Kaukinen, 2002b; Kearney, 2001; Lempert, 1997; Sullivan, Basta, Tan, \& Davidson, 1992). This love makes it very difficult to move on from the relationship, particularly if the woman feels an obligation to care for her abuser (Kearney, 2001). In contrast, some abusive relationships are characterised by high levels of control tactics used by the batterer, causing the woman to feel powerless to leave (Aubrey \& Ewing, 1989; Ferraro \& Johnson, 1983). Furthermore, due to the fact that males often hold the position of greater financial power in relationships, women often see it as impossible to leave (Aubrey \& Ewing, 1989; Ferraro \& Johnson, 1983; Kaukinen, 2002b; Kearney, 2001; Sullivan, et al., 1992). This is exacerbated when women do not have an alternative place to live; do not have a high level of education or employment skills; and are unaware of available resources (Carlson, 1997; Sullivan, et al., 1992).

Women's internalised feelings also provide a barrier to them leaving a relationship characterised by IPV. For instance, often women feel that violence is not a serious issue or that the offender should not be blamed for their actions (Aubrey \& Ewing, 1989; Kearney, 2001). Additionally, many women find ways to rationalise their partner's actions, in order to avoid having to deal with the issue (Ferraro \& Johnson, 1983). When these feelings are combined with a lack of self-esteem and a fear of reprisal 
should they leave, it becomes extremely difficult for a woman who is experiencing IPV to see a way out of her relationship (Aubrey \& Ewing, 1989; Sullivan, et al., 1992; Van Hook, 2000).

A major issue involved with the study of IPV is that there is an incredibly low reporting rate, mostly because of fear of how reporting will impact on others' perceptions of the woman, and the consequences that reporting could have for the perpetrator (Flood \& Pease, 2009; Hayden, 2010; Metzger \& Woodley, 2010; Towns \& Adams, 2009). In order to address this issue, a campaign started in New Zealand in 2006 to attempt to establish the social norm that IPV is 'Not OK' and to encourage reporting (Campaign for Action on Family Violence, Family and Community Services, \& Ministry of Social Development, 2011; Giles, et al., 2005; Metzger \& Woodley, 2010). This campaign has managed to make the issue of IPV more visible, with 85 per cent of New Zealanders reporting having seen the campaign (McLaren, 2010, p. 22). This campaign has had a significant effect on those who have seen it, with 37 per cent of them stating that what they saw had an impact upon their perceptions of IPV (McLaren, 2010, p. 23).

\section{General IPV Help-Seeking}

The majority of women who experience IPV seek some form of help during their relationship (Fanslow \& Robinson, 2010; Kaukinen, 2002b, 2004). Rather than employing one help-seeking strategy, most women seek help from a number of sources (Fanslow \& Robinson, 2010), with Sullivan et al. (1992, p. 268) stating that most women use an average of three to six different forms of support during their relationship. Significantly, women who experience IPV do not only seek help in order to end their relationship or to punish their partner, they often merely want someone to be there for them and for the violence to end (Hayden, 2010; Kaukinen, 2002a; Lempert, 1997; Mahlstedt \& Keeny, 1993; Metzger \& Woodley, 2010). Such helpseeking is an important aspect of a violent relationship, with greater support associated with less negative consequences for a woman's wellbeing 
(Kaniasty \& Norris, 1992; Kaukinen, 2002a, 2004; Metzger \& Woodley, 2010).

Women who experience IPV need to feel that they are ready before they will actively seek help; this state of readiness is linked to their perception of the violence (Metzger \& Woodley, 2010). In order to get to a stage where they feel able to seek help, women often have to overcome many barriers. Two such barriers are feelings that IPV should remain a private matter, and feelings of shame and embarrassment (Allen, 2011; Bui, 2003; Ferraro \& Johnson, 1983; Fugate, Landis, Riordan, Naureckas, \& Engel, 2005; Giles, et al., 2005; Hayden, 2010; Mahlstedt \& Keeny, 1993; Metzger \& Woodley, 2010). Other significant barriers to reporting for women include concerns that they and their families may experience stigma; belief that they will be blamed for the violence; and fear that they will not be believed (Fanslow \& Robinson, 2010; Flood \& Pease, 2009; Fugate, et al., 2005; Giles, et al., 2005; Hayden, 2010; Metzger \& Woodley, 2010). Additional barriers include a belief that the violence is not serious enough to warrant intervention (Fanslow \& Robinson, 2010; Fugate, et al., 2005; Hayden, 2010); a view that the violence will be ignored or covered up by the people they tell (Metzger \& Woodley, 2010); and fear that reporting the violence to anyone will result in further violence from their partner (Hayden, 2010; Metzger \& Woodley, 2010).

Help-seeking can be split into two broad sources; formal and informal (Fanslow \& Robinson, 2010; Mahlstedt \& Keeny, 1993). Formal support comes from institutions within the criminal justice system and organisations such as Women's Refuge; while informal support comes from members of the woman's social networks, such as friends and family. The discussion to follow will focus only on informal sources of support. 


\section{The Importance of Informal Support}

Research on informal sources of support for women who experience IPV is scarce (Davis \& Brickman, 1996; Kaukinen, 2002a; Lempert, 1997; Mahlstedt \& Keeny, 1993; West \& Wandrei, 2002). However, such sources of support are important to the understanding of issues surrounding IPV and the help-seeking behaviour of the women who experience it. Literature, from both international and national sources, states that the support received from family and friends is the most commonly used and most salient form of support for women who experience IPV (Davis \& Brickman, 1996; Fanslow \& Robinson, 2010; Fugate, et al., 2005; Hayden, 2010; Kaukinen, 2002a, 2002b, 2004; Lempert, 1997; Moe, 2007; Van Hook, 2000; West \& Wandrei, 2002). Metzger and Woodley (2010, p. 12), citing a New Zealand study, find that 94 per cent of women who experience IPV seek support from their family or friends. Furthermore, informal support is often sought early on in an abusive relationship, more often than not being accessed long before support from formal sources (Davis \& Brickman, 1996; Fanslow \& Robinson, 2010; Metzger \& Woodley, 2010; Moe, 2007).

Receiving a positive and supportive reaction from family and friends has been found to be a significant factor in seeking help from formal support networks (Fanslow \& Robinson, 2010; Flood \& Pease, 2009; Giles, et al., 2005; Metzger \& Woodley, 2010; Sudderth, Leisring, \& Bronson, 2009). In fact, Kaukinen (2002a, 2002b, 2004) describes informal support as a 'pathway' to formal support. On the other hand, receiving a negative reaction from the first person they tell often causes women to hide the violence further and not seek future help (Giles, et al., 2005; Kaukinen, 2002b; Metzger \& Woodley, 2010). Furthermore, receiving a helpful response from a family member or a friend has a positive effect on the wellbeing of the woman (Mahlstedt \& Keeny, 1993; Metzger \& Woodley, 2010). For example, effective social support lessens the long-term impacts of IPV (Metzger \& Woodley, 2010; Postmus, Severson, Berry, \& Ah Yoo, 2009), and increases self-efficacy and self-belief (Metzger \& Woodley, 
2010), while also making the ability to change or leave the relationship seem realistic and attainable (Giles, et al., 2005; Metzger \& Woodley, 2010; Waldrop \& Resick, 2004). Conversely, having a lower level of social support, or less effective social support, has a negative impact on a woman's wellbeing, evidenced by a greater likelihood of mental illness (Dutton, Hohnecker, Halle, \& Burghardt, 1994) and a reduced probability of ending the relationship (Carlson, 1997).

\section{The Effectiveness of Informal Support}

The perception of social support from friends and family has been found to have a positive effect on the psychological wellbeing of women who experience IPV, including promoting self-esteem and reducing the incidence of mental illness (Dutton, et al., 1994; Kaniasty \& Norris, 1992; Kaukinen, 2002a). However, there is a lot of variation in how family and friends may respond to disclosures of IPV and their responses are not always supportive (West \& Wandrei, 2002). For example, Fanslow and Robinson (2010, p. 943) reported that 40 per cent of women who experience IPV in New Zealand had not been helped or supported by the family or friends they had told. One influential factor in this is the culture of the woman experiencing IPV. Family members from collectivist cultures may be unwilling to intervene in the relationships of others, even going so far as to blame the woman for the abuse (Bui, 2003; Fanslow, et al., 2010; Giles, et al., 2005; Hayden, 2010; Kaukinen, 2004; Snowden, 1998). Furthermore, many unsupportive reactions occur when family and friends think they are being helpful but do not actually know how to respond, rather than deliberately trying to prevent the women from receiving the support needed (Mahlstedt \& Keeny, 1993; Metzger \& Woodley, 2010).

\section{Factors leading to ineffective support}

The most common form of ineffective support is behaviour that has the effect of disempowering or controlling the individual (Metzger \& Woodley, 2010), creating a relationship dynamic similar to that which they share with 
their intimate partner (Lempert, 1997; McDermott \& Garofalo, 2004; Metzger \& Woodley, 2010; Moe, 2007; Rusbult \& Martz, 1995). This, in turn, has a negative impact on the overall wellbeing of women who experience IPV (Metzger \& Woodley, 2010; Moe, 2007). Examples of such behaviour include telling the woman how to define their situation (Fanslow \& Robinson, 2010; Lempert, 1997; Mahlstedt \& Keeny, 1993; McDermott \& Garofalo, 2004; Metzger \& Woodley, 2010); instructing them on how to tell their story (McDermott \& Garofalo, 2004); telling them how they should view themselves (Lempert, 1997); forcing them to leave the relationship (Davis \& Brickman, 1996; Dutton, et al., 1994; Fanslow \& Robinson, 2010; Lempert, 1997; Moe, 2007; Taylor \& Sorenson, 2005); or forcing them to make contact with the criminal justice system (McDermott \& Garofalo, 2004). Furthermore, when people place conditions on their support (Lempert, 1997; Moe, 2007); make unwanted intrusions into the woman's life (McDermott \& Garofalo, 2004); or make choices for the woman (Metzger \& Woodley, 2010) this is generally experienced as disempowering. Additionally, giving an excessive amount of advice (Lempert, 1997; Mahlstedt \& Keeny, 1993; McDermott \& Garofalo, 2004; Metzger \& Woodley, 2010; West \& Wandrei, 2002) or focusing primarily on punishing the offender rather than supporting the woman (McDermott \& Garofalo, 2004) can also serve to disempower them.

Another ineffective form of support occurs when women's fears are realised. For instance, many women find that when they talk to family or friends they are met with stigma (Fanslow \& Robinson, 2010; Kaukinen, 2004); stereotyping as helpless victims (Hillier \& Foddy, 1993); judgement (Metzger \& Woodley, 2010; Moe, 2007; Towns \& Adams, 2009); or blame (Davis \& Brickman, 1996; Giles, et al., 2005; Hillier \& Foddy, 1993; Howard, 1984; Kaniasty \& Norris, 1992; Kingi \& Jordan, 2009; Leisenring, 2006; Mahlstedt \& Keeny, 1993; Metzger \& Woodley, 2010; Taylor \& Sorenson, 2005; Towns \& Adams, 2009; West \& Wandrei, 2002; Witte, Schroeder, \& Lohr, 2006). Fear of reactions such as these often prevents 
reporting in the first place. Blame has been found to be particularly prevalent in many European-dominated countries, including New Zealand (Giles, et al., 2005; Metzger \& Woodley, 2010), and has the effect of reinforcing feelings of self-blame often already experienced by women who experience IPV (Metzger \& Woodley, 2010; Moe, 2007). Other fears are also realised when family and friends do not believe women (Lempert, 1997); trivialise the violence and the relationship (Metzger \& Woodley, 2010; West \& Wandrei, 2002); respond with retaliation and anger (Mahlstedt \& Keeny, 1993; Metzger \& Woodley, 2010; Sudderth, et al., 2009; West \& Wandrei, 2002); or do not see IPV as a problem, but as an aspect of a normal relationship (Fanslow \& Robinson, 2010; Metzger \& Woodley, 2010).

Finally, there are specific characteristics of the support person and the situation that decrease the likelihood that support will be effective. For example, friends and family who do not understand the processes involved with IPV (Metzger \& Woodley, 2010); who have traditional perceptions of gender and relationships (Hillier \& Foddy, 1993; Kristiansen \& Giullieti, 1990; West \& Wandrei, 2002); or who hold violence-supportive attitudes (Flood \& Pease, 2009; Markowitz, 2001; West \& Wandrei, 2002) are less likely to provide women with the support they require. Furthermore, an increase in the seriousness of the violence experienced is often related to a decrease in the quality of support received (Waldrop \& Resick, 2004).

\section{Factors leading to effective support}

In contrast to the factors leading to negative responses from family and friends discussed above, there are a number of factors that have a positive influence on the lives of women who experience IPV. Effective support can start prior to abuse, with a show of support early on in the woman's relationship proving helpful (Fanslow \& Robinson, 2010). Once violence is present, someone who recognises that violence is occurring and initiates a conversation about it, or responds to an approach for help immediately, is 
likely to have a positive influence on the outcome for the woman (Metzger \& Woodley, 2010). From this point onwards it is useful if family and friends remain accessible and keep all information confidential so that women do not feel as though they have been betrayed, especially with unwanted disclosure of personal information (Metzger \& Woodley, 2010). In addition, the more people a woman talks to about the abuse, the greater support they are likely to receive and the more positive this will be overall (Metzger \& Woodley, 2010).

The most important form of support for women who experience IPV is emotional support (Kaniasty \& Norris, 1992; Mahlstedt \& Keeny, 1993). This involves showing genuine concern for the woman's wellbeing (Ferraro \& Johnson, 1983); listening in a non-judgmental way (Gerbert et al., 2000; Kingi \& Jordan, 2009; Lempert, 1997; Mahlstedt \& Keeny, 1993; Metzger \& Woodley, 2010; West \& Wandrei, 2002); helping them to devise a safety plan (Gerbert, et al., 2000; Metzger \& Woodley, 2010); and understanding the dynamics involved in an abusive relationship (Clements \& Ogle, 2009; Kaniasty \& Norris, 1992; Kingi \& Jordan, 2009; Lempert, 1997; Mahlstedt \& Keeny, 1993; Metzger \& Woodley, 2010; Moe, 2007; Sudderth, et al., 2009; Waldrop \& Resick, 2004; West \& Wandrei, 2002). Furthermore, it is helpful when friends and family attempt to empower women who experience IPV (Lempert, 1997; Mahlstedt \& Keeny, 1993; Metzger \& Woodley, 2010), using tactics such as assistance with decision-making (Mahlstedt \& Keeny, 1993; Metzger \& Woodley, 2010; West \& Wandrei, 2002) and helping them to interpret their situation (Lempert, 1997), while making sure that definitions of their role as a 'victim' and decisions about what action to take are not forced upon them. Additionally, women should be reassured that they are not to blame (Gerbert, et al., 2000; Lempert, 1997; Mahlstedt \& Keeny, 1993; Metzger \& Woodley, 2010; West \& Wandrei, 2002), while being reminded that their partner's behaviour is abusive (Gerbert, et al., 2000; Metzger \& Woodley, 2010; Waldrop \& Resick, 2004) and that they are not worthless (Gerbert, et al., 2000; Metzger \& Woodley, 
2010). Finally, an interaction in which there is effective emotional support should be characterised by genuine concern for the woman's welfare (Metzger \& Woodley, 2010); belief in the woman’s story (Metzger \& Woodley, 2010); and mutual trust (Gerbert, et al., 2000).

In conjunction with emotional support, many women who experience IPV find the provision of informational and material support to be extremely helpful (Kaniasty \& Norris, 1992; Metzger \& Woodley, 2010; Postmus, et al., 2009). Informational support often takes the form of presenting women with their options for further action, thus acting as a direct pathway to formal support (Fanslow \& Robinson, 2010; Kaukinen, 2002a, 2002b, 2004; West \& Wandrei, 2002). On the other hand, material support involves providing resources, such as housing or finances, to women when they are needed (Fanslow \& Robinson, 2010; Kaniasty \& Norris, 1992; Kingi \& Jordan, 2009; Metzger \& Woodley, 2010; Postmus, et al., 2009; Sullivan, et al., 1992).

\section{Summary}

In summary, IPV is a pervasive phenomenon with around one third of women in New Zealand having been abused by their intimate partner (Metzger \& Woodley, 2010). This abuse involves physical, sexual, emotional and mental abuse (Denzin, 1984), which has a severely debilitating effect on the wellbeing of women who experience it (GarciaMoreno, et al., 2006; Kearney, 2001). This violence is influenced by patriarchal gender relations (Dutton, et al., 1994; Towns \& Adams, 2009), the effects of which are amplified in some collectivist cultures which value male dominance and are supportive of violence (Nayak, et al., 2003). Societal understandings of IPV are affected by myths surrounding the woman's personality and actions (Aubrey \& Ewing, 1989; Pavlou \& Knowles, 2001; Towns \& Adams, 2009; West \& Wandrei, 2002), which increases the difficulties experienced by women in reporting and leaving violent relationships (Flood \& Pease, 2009; Metzger \& Woodley, 2010; 
Towns \& Adams, 2009). In New Zealand, a marketing campaign is attempting to address these difficulties by reminding the public that IPV is ‘not OK’ (McLaren, 2010; Metzger \& Woodley, 2010).

While most women who experience IPV find it difficult to report violence, it is common for them to seek help at some stage of their relationship, accessing an average of three to six different support sources before the end of the relationship (Sullivan, et al., 1992, p. 296). However, before a woman seeks help certain barriers need to be overcome, so help-seeking often does not take place until later in the relationship (Metzger \& Woodley, 2010). The most common form of support sought by women is from informal networks, with 94 per cent of women who experience IPV in New Zealand telling their family or friends about their experience with abuse (Metzger \& Woodley, 2010, p. 12). When effective, this support can have a positive effect on the overall wellbeing of women, resulting in better outcomes from the abusive relationship (Giles, et al., 2005; Mahlstedt \& Keeny, 1993; Metzger \& Woodley, 2010; Postmus, et al., 2009; Waldrop \& Resick, 2004), while also increasing the chances of women accessing other forms of support (Fanslow \& Robinson, 2010; Flood \& Pease, 2009; Giles, et al., 2005; Kaukinen, 2002a, 2002b, 2004; Metzger \& Woodley, 2010).

While seeking informal support is mostly perceived as inducing positive outcomes (Dutton, et al., 1994; Kaniasty \& Norris, 1992; Kaukinen, 2002a), there is a lot of variation in the effectiveness of such interventions depending on the response received (West \& Wandrei, 2002). In fact, 40 per cent of women who experience IPV in New Zealand receive unhelpful reactions from those they tell (Fanslow \& Robinson, 2010, p. 943), with family and friends often inadvertently disempowering the woman (Mahlstedt \& Keeny, 1993; Metzger \& Woodley, 2010), or reinforcing their fears of blame and disbelief (Davis \& Brickman, 1996; Giles, et al., 2005; Hillier \& Foddy, 1993; Howard, 1984; Kaniasty \& Norris, 1992; Lempert, 1997; Mahlstedt \& Keeny, 1993; Metzger \& Woodley, 2010). On the other 
hand, when friends and family provide emotional, informational and material support to women, the outcomes achieved are significantly more positive (Kaniasty \& Norris, 1992; Mahlstedt \& Keeny, 1993; Metzger \& Woodley, 2010; Postmus, et al., 2009).

Given the importance of informal support systems to women experiencing IPV, discussed above, this study aims to examine the dynamics of disclosure to family and friends. The second chapter of this study will examine the theoretical background and research methodology used, before discussing the specifics of the research design. The analysis chapters which follow report on the experiences of six women who have experienced IPV, including how they experienced the disclosure process and what factors facilitated and impeded this. This analysis is broken into three sections: Personal Factors, such as actions taken and the thought processes involved; Social Factors, including the responses received upon disclosure and the effects of these responses; and Recent Factors, such as ongoing support and reflections on their situations. The final chapter will bring the factors from the three preceding chapters together to form an overarching theory, with recommendations for future research and policy implications presented. 


\section{Chapter 2: Methodology}

\section{Introduction}

This chapter will describe the methods used in this research project. First, I will examine the theoretical underpinnings of the methods used, specifically feminist perspectives, with a focus on feminist standpoint epistemologies, and grounded theory. Following on from this, I will discuss the design of my research. I will start by explaining the aims of the research, then move onto the ethics process and the development of my research instruments. Then I will discuss the processes of recruiting a sample, conducting the interviews and analysing the data. Finally, I will examine the difficulties I faced as a Pākehā ${ }^{1}$ male researching women's experience of disclosing Intimate Partner Violence (IPV) to family and friends, before discussing the caveats of this research.

\section{Theoretical Underpinnings}

Feminist perspectives

Feminist perspectives recognise gender as an important dimension by which society is organised, interacting with other dimensions such as race and class (McPhail, Busch, Kulkarni, \& Rice, 2007). In all dimensions of social organisation there are groups who are at more of a disadvantage than others; this is true of gender with women being under-represented in positions of power and wealth, and single mothers being among the poorest people in society (Letherby, 2003). With this power imbalance in mind, feminist perspectives are used to conduct research for the benefit of women, with women being the active directors of change (Allen, 2011; Letherby, 2003). This approach acknowledges that the experience of marginalised groups generates the most critical questions about a society's make-up and seeks to emphasise "the strength, resilience, and agency of women and strives toward the goals of female empowerment and self-determination” (McPhail, et al., 2007, p. 818).

\footnotetext{
${ }^{1}$ Pākehā is a Māori term, meaning foreigner, which is commonly used to describe New Zealanders of European descent.
} 
Feminist perspectives are the most common perspectives used when researching IPV, focusing on patriarchal oppression as a causal factor (McPhail, et al., 2007). McPhail et al. (2007) state that it is important to have the focus on structural issues that feminist perspectives provide, because if these structural issues are ignored, an analysis of IPV will lack the important examination of power. However, feminist perspectives on IPV are often criticised for not paying enough attention to those who work most closely with the women who experience it, with calls to focus less on the perspectives of academic experts and more on those who have personal experience dealing with IPV (Letherby, 2003; McPhail, et al., 2007). Furthermore, there is a belief that there needs to be recognition of, and solidarity between, multiple feminist perspectives, and that the focus needs to be on both differences and similarities between groups and individuals, rather than promoting 'sisterhood' within a single perspective (Letherby, 2003; McPhail, et al., 2007). Additionally, it is argued that the voices of those women who are most marginalised should be emphasised to avoid reinforcing power imbalances on alternative dimensions such as race and class (Harding, 1993).

While feminist perspectives are important to the study of IPV due to their unique focus on making women's lives more visible (Letherby, 2003), there are no feminist-specific methodologies (Allen, 2011). In order for a methodology to be used in feminist research, it has to have the ability to give women a voice and empower them with the aim of improving their quality of life (Allen, 2011; Harding, 1993). Standpoint epistemologies, with their background in Marxist analyses of master-slave relationships, can be used to provide an appropriately gendered lens (Allen, 2011; Harding, 1993; Letherby, 2003). They examine the perspectives of marginalised groups, with the belief that all people are limited in what they can know, but that more marginalised perspectives provide a more complete analysis of the social world (Harding, 1993). As such, feminist standpoint epistemologies 
begin by examining women's experiences, while also acknowledging marginalisation on other axes such as race and class (Allen, 2011; Letherby, 2003). The fact that standpoint epistemologies are based on perspectives and experiences has caused them to be criticised for not being objective (Letherby, 2003). However, it has been argued that all knowledge, and all ways of measuring knowledge, are socially and culturally constructed and, as such, no research is without bias (Allen, 2011; Harding, 1993; Letherby, 2003). Therefore, it is a strength of standpoint epistemologies that they acknowledge the biases inherent within them (Harding, 1993).

Reality defined by men has very little significance for women (Letherby, 2003), as it is easier for male perspectives to ignore the interactions between women's experiences and their place within society (Harding, 1993). As a male researcher collecting, interpreting and analysing women's experiences of IPV, this could have been an issue for me. However, Harding (1993) argues that women must not claim the ability to do feminist research solely for themselves. She states that coming from a feminist perspective, starting with women's experiences and examining them through a gendered lens, men can also make a significant contribution to feminist research.

\section{Grounded theory}

This research was underpinned by the concepts of grounded theory, as it has the potential to give women a voice and create positive outcomes for them, so fits well with feminist standpoint epistemologies (Letherby, 2003). A qualitative methodology was chosen as it is a more effective way of studying an 'othered' group such as IPV survivors (Allen, 2011), uncovering knowledge about experiences and perspectives that are often neglected (Glaser, 1992). Grounded theory was specifically selected because it "enables the development of a complex, holistic picture of a social or human dilemma using thick, rich description to construct a narrative account of the dilemma in context” (Latta \& Goodman, 2011, p. 978). It also seeks to generate new ideas, rather than confirm old ones (Latta 
\& Goodman, 2011). Furthermore, grounded theory explains all variation within a given set of data (Latta \& Goodman, 2011) and, as such, meets the most important criteria for significant scientific theory - scope and parsimony (Glaser, 1992).

Grounded theory involves a process of systematically collecting and analysing data; identifying themes and categories; and developing a malleable theory which can be adapted throughout the process of ongoing data collection (Glaser, 1978, 1992; McPhail, et al., 2007). Inherent within this methodological approach is the acknowledgement that the researcher cannot completely detach themselves from the data, with personal perspectives and experiences influencing theory generation (Glaser, 1978). Grounded theory is not a verificational process; it is a process of using participants' experiences to generate hypotheses that can be verified at a later date using other methodologies (Glaser, 1992). The generation of a theory is a process that requires creativity on the part of the researcher; not just in discovering new ideas, but in discovering new connections between established ideas (Glaser, 1992).

Grounded theory is used to organise data into dimensions and properties to form a theory (McPhail, et al., 2007). Glaser $(1978,1992)$ argued that this theory must satisfy four conditions; the theory should:

- fit all of the data;

- work, in that it explains everything that has happened, and can predict what will happen in future;

- be relevant to the specific area of action of the research; and

- be able to be modified to fit any new data that emerges.

In order to satisfy these conditions, data are coded and recoded throughout the research process through the use of memos (Latta \& Goodman, 2011). Once a theory has been developed, it is compared to and contrasted with existing literature (Glaser, 1992). 


\section{Research Design}

Research aims

This research aimed to investigate the dynamics surrounding the disclosure of IPV. Initially, I had planned to undertake research into the treatment of women who experience IPV by the New Zealand Police; family and friends; and support agencies, such as Women's Refuge (Refuge). I spent approximately two months drafting a proposal to investigate these issues. However, feedback received during the university review process indicated that the scope of the study was too wide for this thesis. Subsequently, I limited the proposed study to only include female survivors of IPV who were no longer in relationships, focussing purely on their treatment by family and friends. The definition of IPV for this study, as devised in the previous chapter, is 'any situation where a male engages in behaviours of a physical, verbal or psychological nature, directed towards his female spouse or other intimate partner, in an attempt to cause physical or emotional harm AND maintain power and control over her'.

\section{Ethics}

Ethics are an important part of studying IPV, as the research process can lead to re-victimisation (of both an emotional and physical nature) of the participant (Sullivan \& Cain, 2004). I used a wide range of literature to develop an ethics proposal that ensured the safety and confidentiality of the participants. This plan covered issues surrounding finding and contacting participants, gaining informed consent, organising interviews, and safety issues, both for myself and the participant during and after the interviews. Each of these issues will be discussed below, where appropriate. The proposal was submitted to the Victoria University of Wellington School of Social and Cultural Studies Human Ethics Sub-Committee and approved on the $11^{\text {th }}$ of July 2011 (see Appendix A for ethics approval). 


\section{Research instrument development}

Once my ethics application was approved, I conducted three interviews with key informants (see Appendix $B$ for information sheets and consent forms, and Appendix $C$ for the interview guide). The first two interviews were with researchers who have experience in the field of IPV: the first interview was with one male and the second with two females. The final interview was with a male counsellor from the Victoria University of Wellington Student Health Service. These interviews took between twenty and fifty minutes. Interviewees were asked about their experience in the field of IPV; their suggestions for finding a sample; and their advice on conducting interviews in a manner that would not harm the participants in any way. Ideas that came out of these interviews included:

- limiting my sample to university students (this was later found to not be feasible);

- $\quad$ starting the interviews with impersonal questions to build rapport;

- letting the participant lead the interview as much as possible; and

- being completely non-judgemental.

All of these suggestions, except for the first, were adopted.

After I had completed my informant interviews, I began drafting my participant interview guide (see Appendix E). I attempted to develop openended questions that would encourage as much discussion from participants as possible. For instance, questions included: 'Why did you tell some people and not others?', 'How do you feel the people you told treated you?', and 'How has your treatment affected the way you would react if you were to experience intimate partner violence in the future?' This interview guide was used for the first interview, and questions were revised as particular themes and topics emerged throughout the research process. For instance, more specific questions were added, while many of the existing questions were refined in order to better investigate the themes present in previous interviews. 


\section{Recruiting a sample}

The other major aspect of preparing for the interviews was obtaining a sample. While a large sample size is ideal for most studies to attempt to yield statistically significant results, there are often many factors which impact on the ability to obtain such a sample (Yeboah, 2008). In this study a large sample size was not feasible due to the nature of the topic, time constraints, limited funding and the limitations of a Master of Arts research project. The fact that I am male also compounded issues around recruiting a sample.

This was not a random sample; a purposive sampling technique was used, inviting individuals who fit certain criteria to take part in the research (Bachman \& Schutt, 2012; Hagan, 2012; Yeboah, 2008). The criteria for participants were that they:

- were women

- were over the age of eighteen;

- had experienced IPV within the last five years; and

- were no longer in an abusive relationship.

The aim was to gain between five and ten participants.

There were a number of ethical issues to be considered in recruiting research participants. Contacting participants had to be done in a way that minimised the risk of other people finding out about the research, potentially resulting in retaliatory violence towards the participant (Sullivan \& Cain, 2004). Because of this, I contacted the National Office of Women's Refuge requesting assistance in finding participants. The Wellington Office of Women's Refuge then sent my information sheet (see Appendix $D$ ); detailing the purpose of my research, who I was looking for as participants and the procedures involved in the interview; to IPV survivors, giving them the option of contacting me. While Refuge was willing to assist me in gathering a sample, I had to provide an assurance that the details of participants would remain confidential. I was also required to attend a one- 
day Family Violence Training Course provided by Refuge for practitioners who work in the field of IPV. This course related more to dealing with women who were disclosing violence for the first time and who were building up to a point of leaving and, as such, was not directly related to my research. However, it was still valuable as it reinforced for me what had been discussed in informant interviews about talking to survivors in a nonjudgemental manner.

When potential participants contacted me, I used the opportunity to mention further safety and ethical issues to them. Before setting up a time and location for the interview I informed them that I was a male, and offered to bring a female colleague with me if it would make them feel more comfortable (Langford, 2000; Sullivan \& Cain, 2004). ${ }^{2}$ Furthermore, I told the women that they were welcome to bring a support person with them, ${ }^{3}$ and advised them that if they were seeing a counsellor they should let them know that they were participating in this research. ${ }^{4}$ I also reminded them that they could withdraw from the research at any point without any questions; they did not have to answer any questions that they did not want to; and I would not ask any questions specifically about the violence, but that they were welcome to talk about this if they wished. ${ }^{5}$ Once these issues had been addressed, a time and place for the interview was organised.

\section{Interviews}

I conducted six interviews with women who had experienced IPV. ${ }^{6}$ Women were invited to choose an interview location where they felt comfortable and which they felt provided the desired level of privacy. Two interviews took place in cafes, two at the participants' workplaces, one in the

\footnotetext{
2 Personal Communication with Key Informants B and C, 28/02/2011; Personal Communication with Key Informant D, 15/08/2011

${ }^{3}$ Personal Communication with Key Informant A, 08/08/2011; Personal Communication with Key Informant D, 15/08/2011

${ }^{4}$ Personal Communication with Key Informant A, 08/08/2011; Personal Communication with Key Informants B and C, 28/02/2011; Personal Communication with Key Informant D, $15 / 08 / 2011$

${ }^{5}$ Personal Communication with Key Informants B and C, 28/02/2011

${ }^{6}$ These interviews lasted between 25 and 45 minutes each
} 
Wellington Central Library and one in an office at Victoria University of Wellington. Because of the methods used for contacting participants (discussed above), this was a self-selecting sample and was, therefore, not representative. This was most evident in the fact that four of the six participants either worked or volunteered in the field of IPV.

Demographic information was not specifically sought during the interviews, but it was revealed that one of the participants was Irish, another was South American and one was part-Samoan/part-Pākehā; the remainder were Pākehā. Three of them were mothers, four of them mentioned some level of tertiary education and five were currently in paid employment. One participant told me that she was 23 years of age; one told me that she was 31 years old; and for two others I was able to estimate that they were in their early thirties from the timeframes of the events they described. There was no information on the ages of the remaining two women.

Before starting the interview I went through the information sheet with the participants, explaining the purpose of the research, reminding them that their information would be kept confidential and that they were able to pull out at any stage if they wanted. So as not to compromise their safety by risking the possibility of retaliatory violence for participating in the research, I suggested that they leave the information sheet with me after the interview (Langford, 2000). ${ }^{7}$ I then requested that they sign a consent form (see Appendix D) stating that I had provided them with the information sheet; that I had given them the option to bring a support person and to request me to bring a female colleague (none of the participants took either of these options); and giving permission for me to audiotape the interview and then transcribe it.

While there was the potential for safety issues to arise during the interview, I trusted the participants' assessment of the risks in their personal situation,

${ }^{7}$ Personal Communication with Key Informant A, 08/08/2011; Personal Communication with Key Informants B and C, 28/02/2011 
as not doing so would have been disempowering (Langford, 2000). ${ }^{8}$ I was also aware that I needed to remain non-judgemental during the interview and accept whatever the women said without query. Exhibiting disbelief and judgement, or minimising their experiences can also be disempowering for survivors of IPV (Sullivan \& Cain, 2004). ${ }^{9}$ Furthermore, I attempted to make the women feel relaxed throughout the interview by double-checking that they were comfortable in the situation. ${ }^{10}$ After the interview was completed, participants were given a koha ${ }^{11}$ of a $\$ 25$ supermarket voucher to thank them for their participation. Participants were given the option of receiving a transcript of their interview. Three women requested these.

\section{Data analysis}

As soon as possible after the interviews I uploaded the audio recording to my computer and transcribed verbatim what had been said. As I was transcribing I took notes of points that I thought would be useful when developing a theory; some of these notes were written on the transcript and some were written in separate documents. After the first interview I examined the notes and transcript, and used the themes present to review the interview guide for the next three interviews. After the fourth interview, I again examined the notes and transcripts of the interviews conducted so far, and used the recurring themes to preliminarily analyse the data. I then used the draft theory to, again, review the interview guide for the final two interviews. The information from these interviews was then used to redraft the theory. I sorted the data into three categories, which form the basis of the three analysis chapters: Personal Factors; Social Factors; and Recent Factors. These categories are by no means distinct and discrete; in fact, there is significant overlap in many areas.

\footnotetext{
${ }^{8}$ Personal Communication with Key Informants B and C, 28/02/2011

${ }^{9}$ Personal Communication with Key Informant A, 08/08/2011; Personal Communication with Key Informants B and C, 28/02/2011; Personal Communication with Key Informant D, $15 / 08 / 2011$

${ }_{10}^{10}$ Personal Communication with Key Informant D, 15/08/2011

${ }^{11}$ A koha is a gift, donation or offering.
} 
From the point of data analysis onwards, participants' names were changed to pseudonyms. In creating these pseudonyms, I gave each participant a letter corresponding to the chronological order of the interviews (i.e. the first interviewee was A, the second B and so on), and then found a name starting with each of those letters. This was done in order to make it easier for me to remember which pseudonym corresponded with which participant.

\section{Challenges faced}

Going into this research project I expected to encounter a number of difficulties, particularly because of the fact I am a male undertaking his first major research project in a sensitive subject area. I was expecting it would be very difficult to find participants; that people would question my motives for undertaking study in this area; and, possibly, that people would attempt to block me from completing the research. While finding participants did take slightly longer than I had hoped, I did not encounter many of the problems that I had anticipated. I received a largely positive response, not just from my informants, participants and the agencies I dealt with, but also from friends, family, acquaintances and lecturers who I talked to about my research. Some of the comments I received from friends and other researchers included being proud of me for taking on such a difficult and important project, and being excited about the potential of the project.

Langford (2000, p. 135) states that "Investigators must examine how they support the abuse of power by consciously or unconsciously using privilege, gender, coercion, or intimidation in their approach to participants”. This was especially relevant to me because, as a Pākehā male interviewing women who had experienced IPV from male former partners, I was coming from a privileged position. While it was impossible to avoid holding this privileged position, it was possible to attempt to minimise the effects of this by being mindful of my position. This reflexivity and awareness of my privilege was made easier by the fact that I identify as a feminist. Throughout the interviews I let the participants take control; I endeavoured 
to make them feel comfortable; and never questioned the validity of any comments they made. Furthermore, I attempted not to impose my own cultural values on them in any way. This was assisted by the fact that most of them were of European descent, but I still had to be aware that some of these women were, in fact, from different cultures to my own.

\section{Caveats}

As mentioned above (under recruiting a sample), this research used a small, unrepresentative sample. As such, the results cannot be generalised to all New Zealand women who experience IPV. However, in using a grounded theory methodology this research was attempting to generate a theory which can be verified at a later date by further studies using different methodologies and more representative sampling. As such, the generalisability of the results was not that much of an issue. 


\section{Chapter 3: Personal Factors - Actions and Thoughts}

\section{Introduction}

This chapter analyses the factors internal to the women that influenced the dynamics involved in their disclosure of Intimate Partner Violence (IPV). The first section of this chapter examines the actions taken by the women, such as who they disclosed to and when they disclosed. The second section examines the personal barriers to disclosure that the women faced, including not recognising their situation as abusive and feelings of embarrassment. The reasons for disclosing are then discussed, before the chapter concludes with a comparison to the literature on violence against women in order to situate these findings within the wider research context.

\section{Actions Taken to Manage the Situation}

This section examines the actions the women took to manage their situations. Within this, the varying stages at which the women disclosed are discussed, alongside the actions they took in order to hide the abuse. This is followed by an analysis of the people the women disclosed to and the factors they took into account in determining their disclosure. The data for this section was obtained using questions such as 'Did you tell your family and friends about your experience?'; 'At what point did you disclose?’; and 'How many people did you disclose to? What influenced your decision to tell them and not others?'

When the women disclosed

Some of the participants were very selective about what they were willing to tell people at different stages of the relationship. One example of this was Annette, who actively tried to hide the abuse while she was still in the relationship. She recounted a story as an illustration:

[I] turned up to family barbeque once with a black eye while I was within this relationship, and then came up with this totally ridiculous story about cooking and these pots falling on my head, and no-one questioned it. And I was really nervous at the time. 
No-one challenged her story, leaving her relieved that she could hide the abuse for as long as she wished. Dani, whose relationship with her expartner was on and off over a number of years, also did this to an extent:

There's heaps of times where our relationship has ended so I've talked about [it] more, probably, at the end and really kind of vented how I've felt about it and kind of gone more in-depth after it's been over. And then in the times that we've been in a relationship together I sort of gloss over the crappy parts more and then am more honest about it at the end.

Dani later went on to explain that she deliberately lied about what she was going through and 'sugar-coated' things, so that people would not judge her as much. She felt that it was important to be able to give people information on her own terms, as she feared being judged for staying in the relationship.

While these were the only two participants to talk about actively hiding the abuse, most participants did not tell anyone until after the relationship had ended. Frances talked to people as soon as the relationship was over, while both Annette and Chloe started talking to people as soon as they could be sure that the relationship was definitely over. Both of them spent two to three months trying to work things out with their former partners before they were confident that the relationships were permanently over, and it was only after this time period that they were comfortable with disclosing. As Annette described:

You know how break-ups are always very messy; there was probably a period of a couple of months where initially I didn't tell people what the reasons were. And then once I became more certain in the idea that it was over and felt the relief of not having to manage this person anymore and his crazy behaviour, I think I felt the need to tell people... As soon as I was sure within myself that I definitely wasn't going back, then I felt like I could tell people.

For Bianca, the decision to disclose took longer, with her only starting to tell people when she realised that there were emotional issues stemming from her relationship that had not been dealt with. However, there were exceptions to this trend. For instance, Erica had sought support from her family and friends throughout the relationship, while Dani reported 
'venting' to people during periods when she and her partner were apart. Judging by the responses they received (which will be discussed in the following chapter), these decisions appear to have had a major impact on how these women were treated by their family and friends.

Who the women disclosed to

Most of the participants reported being very selective about who they disclosed their experience to, with varying reasons for this. Annette described this selectivity:

I've been really selective about who I've told...Like I say that I've told my two sisters, one sister I've told everything to and one sister I haven't told the high level [crazy incidents], because I don't think that she can manage them.

While Annette was clearly worried about upsetting her family, she was also concerned that some of her family might try and take action against her former partner. She discussed how culture was an important factor in this decision:

I haven't told my mother, who is Samoan, or any of my male cousins who are Samoan, because I'm worried about the ramifications of that, that they may approach his family. And they could certainly have grounds to seek some type of restorative justice if they felt that way. So I haven't told them either.

Bianca still did not want her parents to know because she was concerned about how they would view her because of it. They never approved of her former partner, so she feared that if she were to tell them their response would be "I told you so...You're stupid 'cause you stayed there”. Chloe's reasons for being selective in who she told were based on practicality more than anything else. She initially did not tell her friends about her experience because she was living in New Zealand and they were living in South America, which made it difficult to talk to them about it. However, even when she did go back to South America she has never felt the need to talk to any of her aunties or uncles about it. Dani regularly talked to her mother about her situation, knowing from past situations that she would always be there to support her. She explained that she would not feel comfortable 
talking to her younger brother about her problems, and she had no contact with her father at all, so the only family member that she could talk to was her mother. In contrast to this, Erica and Frances talked about their experiences much more freely, not being as selective in who they told.

This process of selecting who the women told what, and when they told them, was described by Annette as an attempt to manage the situation. As she explained:

When you're in the relationship you get so used to managing people's reactions and behaviours...I was in the same sort of mind frame when I came out of the relationship and I was still doing that same role even when I was seeking help [and] trying to heal.

A number of times during her interview she emphasised the need to manage her situation throughout the relationship and ever since. From doing everything she could to hide what was going on during the relationship, to talking exclusively to people who she felt could handle the information and would not confront her ex-partner, she made sure that she had as much control over the situation as possible. However, Chloe's experience contrasted with this quite strongly. She stated that she never gave any thought to who she wanted to know and who she did not, saying:

I don't even care much what people think, I'm that kind of person. [It is] hard enough to sort your own shit out to care about others, it's just too big, you just can't take that big. You just care about you and your closest people, the rest - pfft.

Interestingly, this seems at odds with the actions Chloe actually took in not telling her aunties or uncles why her marriage had ended. However, she did not explain why she never told her aunties or uncles other than to say that they never asked, so it is not clear whether it was a conscious decision or just a case of the subject never being brought up.

\section{Reasons Not to Disclose}

This section discusses the reasons the women gave for not disclosing. In order to obtain the data for this section, there was one primary question that was asked: 'Were there any barriers to disclosure?' The major issues 
discussed in this section include not recognising abuse; expecting that their partner would change; shame; and the fear of disappointing other people, followed by a discussion of other, less commonly reported reasons.

\section{Not recognising abuse}

The most common reason for not disclosing the violence in their relationship was that the women did not recognise that what they were experiencing was abuse. To this end, Dani stated that it is impossible for a survivor of IPV to be helped until they are able to recognise and accept that their relationship is abusive. Erica also said that it was extremely difficult to "be convincing someone else when you're still trying to figure it out for yourself". As Annette and Bianca were young when they became involved in their relationships (late teens), they thought that what they were experiencing was an aspect of normal relationships. Bianca stated that she spent six years telling herself that what she was experiencing was normal, and even now she thinks that it cannot have been that bad because she survived.

Chloe and Dani did not realise that it was possible for someone to be psychologically abusive, and so when they experienced this they initially did not consider doing anything about it. On this point, Dani said that:

I know it's not okay to say you're going to kill someone but I also know that when people get angry sometimes they say stuff that they don't mean. But what I didn't understand was that there's saying stuff that you don't mean when you're angry and then there's being psychologically abusive, and I didn't even know that was an actual type of abuse. I kind of see it now, that he was intentionally doing things to pick fights so that he could then turn around and say really nasty stuff, and so he could blame me for saying horrible things. And I kind of see now what was wrong with it all but I just didn't understand for so long.

For Erica the situation was extremely confusing. Her ex-partner was only ever abusive to her in private, so she spent most of her relationship trying to figure out what she was doing differently in public compared to at home. Furthermore, because she thought that she was to blame she tried to assert her position, which he responded by escalating his violent behaviour. 
For Annette, the situation was made more confusing because she had never witnessed IPV before. Her circumstances left her in shock, trying to figure out why things were going wrong and what she could actually do about it. Dani was in a similar situation, where the majority of her experiences with IPV were what she had seen in the media:

In my mind the only times I have ever seen domestic violence on $T V$ and stuff in relation to New Zealand culture has been like Māori women are emphasised more...And I think that that stereotype made it harder for me to kind of get that help...The other thing is I thought it only happened to old people. So the first time they [Women's Refuge] got in touch I just thought 'I don't really need this help because I'm not the type of person to get abused'. Actually, anybody can become a victim of abuse and that's been a big learning lesson for myself to just realise that it's not just minorities.

For Bianca, recognising the behaviour as abusive was made more difficult because her ex-partner demanded so much time and energy that she was constantly exhausted. It was only after the relationship had ended that she figured out why she was always so tired, and was able to reflect on his abusive behaviour.

A related issue mentioned by some of the participants was that they were reasonably young and inexperienced with relationships when they became involved with their former partners, beginning the relationships in their late teens. Annette mentioned that it was her first really serious relationship, and she did not really know what to expect. Similarly, Dani said of her expartner:

This is a person I met in my second year of uni so I hadn't really had any really serious relationships and stuff. And I didn't grow up with my mum and dad together so I've never seen what a normal relationship looked like.

Annette said that a symptom of being so young was that her expectations of relationships were based on stereotypes from romantic books and movies. This led to an exaggerated intensity and sense of drama within the relationship which could not be sustained. The effect of this was that: 
[The] stakes were so much higher all the time so everything seemed really, really dramatic...And then you felt like you couldn't really walk away from it.

Bianca experienced a similar intensity due to the fact that her partner was very different to anyone she had ever met before. She stated that, because of this, she was more in love with him than she had been with anyone in the past, and so was intent on doing what she could to make the relationship work.

\section{Expectation of change}

Another common reason for not disclosing the abuse was an expectation that their partner would change their behaviour and, as a result, the women were not ready to leave the relationship. The importance of this expectation was summed up by Chloe when she stated that:

I always say that I left him because he didn't want to do something about it, not because of what he was doing but just not wanting to change.

She was so committed to changing his behaviour that she moved to New Zealand from South America in the hope that changing their environment would make him change. However, the abuse escalated after they relocated.

Annette was used to being in control of her life. Because of this, she thought that if she put enough effort in, she would be able to make her relationship work:

I was also really determined to make the relationship work and to sort of fix this person that I was with. And I felt like I was protecting us as a unit and that I had to manage his behaviour and keep that really hidden from my family. Because...I suppose a part of me knew that if anyone knew what was going on they would make me do something that perhaps I wasn't quite ready to do. I wasn't quite ready to acknowledge that I probably couldn't change the situation.

Bianca reported similar feelings. She said that she never even considered ending the relationship and maintained the attitude that "I' $m$ in this relationship; I'm just going to try and get it to work". However, unlike Annette, she did not see herself as being solely responsible for changing her 
partner's behaviour, stating that she kept thinking to herself that he would change because he loved her. Both of these women spoke of continuing to hope for change after their relationship had ended. Bianca continued to provide her ex-partner with support, of a financial and emotional nature, after they had separated. It was only after he assaulted her once more that she made the decision to completely remove him from her life. Annette stated that even once she had left the relationship, she was still holding onto hope that her ex-partner would change and be a 'better person'.

\section{Shame and fear of disappointing others}

Three of the women reported that they did not tell anyone because they feared what people's reactions would be. Annette described how she was concerned that her experience of IPV would make her family disappointed in her:

Entrenched in that is the shame, I suppose, of being in this place and not really realising how you got to be this person. And thinking that that was really, sort of, the stigma attached to being a victim of domestic violence [and it] wasn't who I was in the eyes of my friends and family. They had seen me as being this really strong person and, to some extent, I felt, especially in terms of my mum...that she would've felt really, really hurt and let down that I wasn't stronger.

Both Bianca and Dani were concerned that they would be seen as stupid for remaining in the relationship. As mentioned earlier, for Bianca this was made worse by the fact that her parents had never approved of her partner, so she was afraid of them saying 'I told you so'.

\section{Other reasons}

There were other reasons given for not disclosing which were less commonly reported. For instance, Chloe and Erica both reported having a lack of opportunities to disclose. Chloe compared her experience to when someone is feeling depressed:

I don't know how you are, but do you contact your friends and say 'Oh, I'm feeling down today'; no usually you don't contact anyone. If you are feeling down you stay at home, depressed in 
your bed, that's what you do. I do at least; I don't call anyone to tell them I'm down and to tell them my problems.

Erica found that between realising that the behaviour was abusive and being brave enough to approach someone for help, there were a lot of barriers to overcome. Chloe echoed these sentiments, while also saying that she was concerned about the effect that it would have had on her parents:

I didn't want them to suffer either. You know it's kind of like I know my parents have been together for 40 years, they're kind of old fashioned, you know, how do you start? Sometimes it's like how do you start?...You have to come a massive way from realising what was going on; accepting it and wanting to change; and having to tell the world, and fuck it's not easy.

\section{Reasons for Disclosure}

This section examines what the women wanted to achieve when they disclosed. The information in this section came mostly from the women's answers to the question 'What were you looking for in disclosing?' This discussion starts by describing the women's desire to 'vent' and get their story out as part of the healing process, followed by their desire to gain a better understanding of their situation, and get reassurance of their feelings and actions.

Annette, Chloe and Bianca felt that disclosing was part of the healing and letting-go process. Annette did not want to take any action against her former partner, instead:

I just needed to say it to someone, and not for it to be this hidden secret thing that I'd have to carry forever...I felt like I needed to tell people close to me...I suppose the longer I was out of the relationship the more I started to feel angry about the way that he had behaved. And I suppose I just needed someone else to know that there was a different history from the one...that everyone else thought that there was.

Annette felt that this was particularly important with her sisters, who she is very close to. She believed that hearing the words out loud was a major part of the process of accepting what had happened to her so that she was able to move on. Chloe summed this feeling up by saying: "If everyone knows your 
lowest part, your darker parts, there's nothing else”. Letting her family know what had been going on was important for her to be able to put the relationship behind her. Bianca took longer to disclose, after she realised that she had not dealt with the emotional issues stemming from the relationship. Like Annette, she also did not want to take any specific action against her ex-partner, she just wanted to vent her frustration and for people to realise what had happened in her relationship.

For Dani and Erica, gaining an understanding of what had been going on was also important. As Dani stated:

I think the first few times I told people [it was] because I was sort of shocked by his behaviour...If you see someone do something that's wrong you kind of tell someone about it...At first I think I was trying to decide whether it was right or not.

Erica echoed this confusion, worrying that it was not as important as she thought it was:

I was checking my own understanding. So you get to the point where you're so confused that you're not sure whether you're making a mountain out of a molehill or not. So you start to say 'Well this is what happened, what do you think?'...You're just checking your own thinking around it. Because they're [abusive partners] so convincing that you're the one that's mad, and you're the one that has the problem [that] the only way to get out [of] that is for someone to convince you that you're not.

For Bianca it was important that she got reassurance that what she was feeling was okay, and that she was not being irrational about it. Unlike the other participants, Frances was not thinking about any support for herself when disclosing, stating that "I just wanted support for my children".

\section{Summary}

Four of the six women in this study did not disclose to anyone while they were still in the relationship. This is consistent with a number of studies which find that many women do not seek help early on because they fear that they will be required to end the relationship (Fanslow \& Robinson, 2010; Fugate, et al., 2005; Metzger \& Woodley, 2010). Metzger and Woodley (2010) further state that women often will not disclose at first 
because of a desire to protect the abuser, but will often be 'ready' once they have had enough of the violence. The results of Bui (2003), and Fanslow and Robinson (2010) also support this study's findings that close family and friends were generally the first to be told. Furthermore, one women's decision not to tell anyone who she feared would confront her ex-partner is also consistent with other research which finds that women who experience IPV often cite a fear of retaliation as a reason for non-disclosure (Metzger \& Woodley, 2010; Sudderth, et al., 2009).

The finding that it was difficult for women to identify their situation as abusive is also consistent with the literature. For instance, Metzger and Woodley (2010) report that many women feel that violence 'creeps up on them', while Hamby and Gray-Little (2000) find that women can identify other people's situations as abusive more easily than they can their own. Furthermore, many studies find that women often do not recognise that what they are experiencing is abuse because they feel it is not serious enough, particularly when there is not a high degree of physical violence resulting in hospitalisation (Fanslow \& Robinson, 2010; Ferraro \& Johnson, 1983; Flood \& Pease, 2009; Fugate, et al., 2005; Skelton \& Burkhart, 1980; Sudderth, et al., 2009). Additionally, Taylor and Sorenson's (2005) claim that women find it more difficult to acknowledge abuse when those within the relationship do not fit societal stereotypes is consistent with most of the women's experiences in this study. This is also consistent with a wide range of literature on the related topic of sexual violence, which shows that when those involved are not lower-income, poorly educated ethnic minorities, people are less willing to accept that violence is happening (Black, 2011; Clements \& Ogle, 2009; Lamb, 1999; McDermott \& Garofalo, 2004).

The fact that half of the women did not initially disclose because they thought their partner would change is also supported by the literature. A number of studies report that women often feel responsible for making a relationship work and comforting their abuser, because society expects that 
women will be nurturing and caring, and sees keeping relationships intact as a priority (Carlson, 1997; Ferraro \& Johnson, 1983; Giles, et al., 2005; Kearney, 2001; Metzger \& Woodley, 2010; Taylor \& Sorenson, 2005; Towns \& Adams, 2009). Furthermore, many women stay in relationships because they believe that their partner's love for them will cause him to change his behaviour; because their partner has promised to change his behaviour; or because they have strong feelings of commitment (Denzin, 1984; Fanslow \& Robinson, 2010; Metzger \& Woodley, 2010; Rusbult \& Martz, 1995; Strube \& Barbour, 1983). In order to justify staying in this situation, many women emphasise the positive, more affectionate parts of their relationship, while attributing the abuse to external factors such as stress or the effects of alcohol (Carlson, 1997; Ferraro \& Johnson, 1983; Lempert, 1997). While this was not specifically reported in this study, it could partially explain why the women were committed to fixing their relationships, particularly Bianca who explained that the abuse only ever occurred when her former partner was drunk.

Three women reported being afraid of how the people they told would respond to them, particularly in respect to being judged about their experience. This is consistent with the findings of other research in which women feel ashamed and embarrassed about finding themselves in such a situation (Allen, 2011; Bui, 2003; Ferraro \& Johnson, 1983; Fugate, et al., 2005; Mahlstedt \& Keeny, 1993; Metzger \& Woodley, 2010; Moe, 2007; Sudderth, et al., 2009). Furthermore, many other studies find that women fear others will blame them for their situation (Carlson, 1997; Flood \& Pease, 2009; Fugate, et al., 2005; Kearney, 2001).

Similar to the participants of this study, the literature suggests that many women do not disclose in order to find solutions; instead they just want to discuss the situation with other people (Lempert, 1997; Mahlstedt \& Keeny, 1993; Metzger \& Woodley, 2010). Many women disclose in order to confirm that what they have been experiencing is abusive; to gain a greater 
understanding of abuse; and to get reassurance about their situation (Allen, 2011; Lempert, 1997; Mahlstedt \& Keeny, 1993; Metzger \& Woodley, 2010). In addition, consistent with Frances' desire to gain support for her children, Metzger and Woodley (2010) report that concerns surrounding children are often a catalyst for women seeking support.

The Personal Factors reported by the women significantly interacted with the Social Factors and Recent Factors that will be outlined in the following chapters. While the women clearly had specific forms of support in mind, as outlined under 'reasons for disclosure', they did not receive this from everyone they disclosed to. However, it will be seen that the women who disclosed during the relationship received more negative reactions, as people actively withdrew their support. Furthermore, a number of reasons that the women gave for not disclosing are closely related to the social barriers to disclosure which are covered in the following chapter, with many of these issues, along with subsequent negative reactions, stemming from a lack of understanding of IPV. 


\section{Chapter 4: Social Factors - Barriers, Reactions and Effects}

\section{Introduction}

This chapter focuses on the social factors involved with the disclosure of Intimate Partner Violence (IPV). The first section discusses the social barriers to disclosure, including the silence of family and friends, and prevailing stereotypes surrounding IPV. The second section of this chapter explores some of the negative reactions which the women received upon disclosure and the effects that these reactions had, including family and friends' withdrawal, and the stigma experienced by those who were single mothers. The third section of this chapter examines the positive reactions to disclosure and the effects of these actions on the women. This chapter concludes by comparing the findings to the wider violence against women literature.

\section{Social Barriers to Disclosure}

The discussion of social barriers to disclosure includes information gathered from participants' answers to questions such as 'Were there any barriers to disclosure?' and 'Did people make it easy to hide the violence?' This section starts by looking at the silence of family and friends, followed by an examination of societal stereotypes and attitudes; social isolation; and the impact of the women's previous experiences.

\section{Silence}

The women in this study were unanimous in their comments that people noticed that there was something wrong in the women's relationships but refused to say anything about it. As an illustration of this point, Annette stated that when she did tell people no-one seemed surprised:

No-one was shocked, I think, which was quite interesting. No one-was like, 'Wow, I could never see him doing that'. Because I think that people saw that there were elements in our relationship that weren't okay. And I think that they saw him being quite controlling and they had seen a gradual change in 
my personality over the course of six years. I think the main reaction was 'Wow, this really makes sense now'.

Annette went on to explain this further. While she had been trying to hide what was going on for the majority of her relationship, looking back she can see that she was not successful in this:

A wide range of people saw my ex act in ways that, it certainly wasn't grey, it was just not okay and no-one ever talked about it or checked in or anything. So I suppose everyone enabled me to keep this big secret that probably wasn't as secret as I liked to think.

Annette felt that her partner's family certainly knew what was going on, but made no attempt to help her out; saying that all she ever received from people who were closest to him was "resounding silence and closed walls".

The fact that people were aware of something going on, but did not want to do anything about it was something that Bianca found also. She can remember a number of times when her friends saw her ex-partner acting inappropriately, but found that they were never willing to intervene:

We'd be out with friends and he'd flip his nut again and grab your wrists and hurt you, but not in a way that was too OTT [over the top], but still not okay. It's not the kind of thing that normal people would do. And your friends would see that...I think they realised that something was off but they didn't really think...[she trailed off at this point].

Chloe's mother knew that her husband was preventing her from spending time with her sisters and friends, and would talk to him about it. However, she never said anything to Chloe. This was, however, more action than anyone else took, and left Chloe feeling extremely frustrated at the situation, saying "What the fuck? No-one asks you, no-one gives you the chance to do it [talk]". Dani found that no-one, not even those she had told about it, asked her if she was okay. With respect to trying to hide the violence from people, she wondered whether she was a good lair, or if people wanted to pretend that nothing was happening. Erica has found out since she left her partner that people definitely knew what was going on, but the only times she ever got the chance to talk about it was when she initiated the conversation. 
The women felt that the reasons that no-one ever asked them about the abuse was a mixture of discomfort, embarrassment and not viewing IPV as their problem. To this end, Annette remarked that people are willing to avoid talking about things that are 'yucky', especially if someone wants to hide it. Additionally, Bianca said that people do not want to talk about IPV because people find it far more uncomfortable than they should. She compared it to sexually transmitted diseases as a problem that no-one wants to openly talk about. Dani agreed with this sentiment, using a different example:

I don't think it's talked about very much, 'cause it's kind of right up there with other taboo subjects like abortion. People don't talk about that over coffee; neither do they talk about domestic violence.

Erica and Frances took this a step further, saying that people seemed to think that there was something wrong with them, similar to a disease, that they could catch just by being associated with them. Frances elaborated:

People don't want to know, they just don't want to know. Because somehow they feel it's catching, it's going to taint their lives, [and] they don't want to know. [Even] people that I was very friendly with...they keep away from you.

Erica also found that people who knew about it did not mention anything because they were too embarrassed:

Yeah and extended family have said to me...'We're so sorry; we just didn't know what to do. You know, we were really embarrassed but we didn't know what to say to you, so we didn't see [you]' You know, they don't see you 'cause it's embarrassing.

Erica, Frances and Chloe felt that people did not think that IPV was their problem. All of them remarked that people did not want to think about it because they did not want to have to do anything about it.

\section{Stereotypes and attitudes}

A widely reported barrier to disclosure was the attitudes that were held by other people. The most common attitude was the stereotype held about people who experience abuse in relationships. In particular, there was a 
prevalent stereotype of IPV only happening to people who are Māori, from a lower socio-economic background and poorly educated. As most of the women interviewed for this study were Pākehā, from middle to upper socioeconomic backgrounds, with a reasonable standard of education, it meant that others found it difficult to accept that IPV could happen to them. As Erica explained:

[In] our socio-economic group, I guess, there's this disbelief - it doesn't happen in here, it doesn't happen to us...It's sort of like, it's icky stuff [that] happens to someone else over there and not to us.

Bianca further elaborated on this point:

I think that's also a confusion...It's actually a real mixture [of people], and I think people forget that it's not just those low income, don't have any support system kind of people. It's actually everybody, 'cause you don't see that. You only hear about the one kind and that's really sad...It's actually rife across the whole spectrum [of society].

This stereotyping was something that continued to hinder the women once they finally disclosed the abuse. Bianca recalled the shock that many people showed when she told them, with many being confused that it had happened to her because she had a job and was educated. While this was more a reaction of surprise than one that actually caused her problems, Frances had a much more negative experience:

Someone said to me 'Frances, you are the wrong colour and the wrong socio-economic group'...If I was Māori and low-income I'd have been listened to, and they'd have believed that the father of the children did this regardless...But because he's white/Pākehā, we lived in the top street in [a wealthy suburb]; there was the disbelief from the start. It's funny that people think that domestic violence is confined to lower socio-economic groups, it's not.

Such statements relate to Dani's comments in the previous chapter regarding her own preconceptions about the people who experience IPV. The perception that IPV only happens to Māori women from disadvantaged backgrounds makes it harder to accept that there are affluent, well-educated, Pākehā women who have the same experience. In turn, this makes it more 
difficult for women who do not conform to prevailing stereotypes to find the assistance they need.

Annette also found that people were quick to judge the character of women who stay in violent relationships. This made it harder for her to openly admit being in such a position. She stated that:

People who don't really understand the dynamics of what those relationships look like, I think, definitely judge you for being weak or foolish, or whatever.

The fact that one of the major reasons Annette gave for not disclosing was a fear that she would be judged and that people would see her as weak, shows just how important this attitude was in preventing her disclosure. Dani also found that dominant attitudes regarding women in violent relationships contributed to her hiding what was going on in her relationship. She described how her mother, who she reported as being her biggest source of support, held negative attitudes towards women who experience IPV. She remembered an incident from when she was younger:

When I was about fifteen and I was walking along the road [and] there was a lady being beaten up outside by this guy and you could hear her stomach being kicked...And to my mum I was like, 'Don't you think we should call the Police?' and her attitude was...you don't get involved in domestic violence because the woman is stupid enough to go back anyway. And she's like, 'And women get angry when other people interfere as well'.

In addition to this, Dani's mother told her a number of times when she was growing up that abusive partners do not deserve a second chance:

She would always say to me 'If a man ever hits you, you leave. 'Cause you only let a man hit you once and then they never get a second chance'. So, yep there's this expectation that if you are in a relationship and are abused then you leave. And I think the problem...with my experience [was that] there wasn't much physical abuse as much as there was the psychological/emotional stuff....It doesn't start off with hitting...It was never like just one punch and then 'Oh yeah, I'll leave'. It's just never been like that, so you get sucked in way more. 
Such attitudes expressed by Dani's mother when she was younger stayed in her mind, and seemed to have an enduring effect. She remembered thinking that, if this was the attitude of the most supportive person she had contact with, it was likely that many others would also view her negatively for staying in the relationship.

Chloe encountered other attitudes that kept her in the relationship. Her and her ex-husband used to live on the same property as his parents, and she felt that they had overheard the abuse at some point, and in some ways they even supported it. His father held chauvinistic attitudes, and would often denigrate Chloe. Despite the fact that Chloe had a much higher level of education than him, her ex-husband's father would often tell her that the role of women should be confined to that of mothers and house-wives. He would say "Oh you're stupid, I know more than you and why'd you waste your time going to uni?". For Chloe, this made the situation more difficult, and it was not until she moved away from that environment in South America, to New Zealand, that she was able to take action to ensure her safety.

\section{Social isolation}

Two of the participants described how isolated they were throughout their experience, explaining that this was one of the most difficult aspects when trying to seek help. Erica talked about the way in which her ex-partner purposefully isolated her from friends and family throughout their relationship:

He didn't like me talking to friends and family...And people weren't comfortable to come round, so the kids' friends didn't come round and, therefore, that was that whole social sector just, sort of, gone.

This was an experience that was shared by Frances, with her ex-partner telling his work colleagues that she had mental health issues. She was also further isolated by the actions of her family who wanted to ignore the abuse 
that was present in their own family when they were younger, she explained:

There's a lot of money at stake in my family, there's only my mother left now...There's a lot of money at stake, so no-one wants to rock the boat, you know? Mum wants to pretend that everything was lovely and wonderful, and those who agree with her will get the money, and those of us who don't will get nothing.

As a result Frances was extremely isolated from her family, removing a significant source of potential support. Erica explained the effects of isolation further, particularly in respect to being of a higher socio-economic background:

I think that we've lost, in a sense, the need for community, and that's just as important in our socio-economic group as in other cultures [sic]. The isolation is the worst thing, THE worst thing and while we all say it's not okay, we don't have any supports to pick up round those people once they've got out of there...You really are all alone. So, you know, you think of those old days where the community would've known that something had happened.

For both of these women, they were stuck in a position where they had been completely cut off from potential sources of support, and so they felt as though they were going through their experience without anyone to turn to.

\section{Previous experiences}

The final barrier mentioned was previous experience. However, this was a barrier to disclosure for only one participant. Bianca's parents were always very negative about her former partner. She explained:

My parents never, actually, really approved of him anyway...They were kind of like, 'Why is she with deadbeat', you know like, 'He's not doing anything'...They sort of always said to me, 'Why are you even with this guy? He doesn't seem to be the kind of guy you'd go for'... I just didn't really want to revisit [it] with them...'cause I think they were kind of disappointed anyway, [and] it would just make them even more disappointed.

For Bianca, this negativity from her parents made it very difficult for her to talk about her experience, and so she had still not disclosed to them at the time of the interview. However, the fact that she was the only participant 
who had such an experience makes it difficult to say whether this was something specific to her, or whether this is something that is more widely experienced. However, for Dani, previous experience also shaped her responses to victimisation, in this case making it easier for her to disclose. As she explained:

It's easy to be quite open with my mum because I had a really abusive experience when I was really young...[and] I learnt my mum loves me no matter what anyway, so it's always been easier to be open with her about stuff.

As can be seen from these two extracts, previous experiences of either support or negativity can have a major impact on the actions taken by women who are abused by their partners.

\section{Negative Reactions}

This section explores some of the negative reactions which the women received upon disclosure, and the effects that these reactions had. The information within this section was gathered using questions such as 'What actions were not helpful?' and 'How did these influence your actions?' It begins by examining withdrawal and ignoring; people not understanding abuse; judgement and disbelief; the stigma of single motherhood; and imposition of ideals upon the women by other people. The effects of these negative reactions are then discussed.

All of the participants in this study experienced some negative reactions upon disclosure. For Frances and Erica, these negative reactions outnumbered positive ones, while Dani's friends engaged in many of these behaviours. The other participants had a more positive experience overall, however all of them reported examples of negative reactions.

\section{Withdrawal and ignoring}

Three of the women found that the people they told about their experience avoided them from that point onwards. For instance, Annette described one of the few situations when she disclosed during the relationship: 
I remember telling a mutual friend...and she had told her partner, and then they, pretty much, just withdrew from me completely. And I know that they're still friends with him.

Similarly, Chloe explained how she and her ex-husband had made friends with a number of people after they came to New Zealand. Once she left him they stopped talking to her. For Frances this experience of avoidance was ongoing. She explained that even at the time of the interview, a number of years since her experience, when she talked to people about it she often found that they were uncomfortable with her because of it:

Some people can't hack it, you know, [and] some people can. And there's fewer of the ones who can, and it depends basically on their own relationships. Sometimes it'll be that they'll go home, chat to their husband, or whatever, and then you won't see much of them after that.

There were also occasions when participants' attempts at gaining support were ignored. Annette tried to take action the first time her ex-partner abused her in public:

[I approached] one person who witnessed him smashing up my car and trying to punch me. He was my ex-partner's brother-inlaw, he's a really nice, reasonable guy...[and] we always got on reasonably well together. And I remember being incredibly embarrassed that my ex had taken it to this really public place, whereas normally I could manage it 'cause it was really behind closed doors. And I had text[ed] him and wanted him to meet me for a coffee, because I think I just wanted him to help me change my ex, like, 'You've seen this, I want you to help me, how is this okay?' And he never responded...it was just kind of resounding silence.

Bianca's former partner assaulted her one night in the middle of town, and she recalled a police officer standing nearby, who did nothing. She felt that this reflected an attitude where people are willing to rationalise or minimise violence. She explained:

'Oh well, that's just young kids having a fight'. But it's kind of like, 'So what if it's young kids having a fight?', which it wasn't, I was in a relationship with this guy. How would he know what was going to happen when I got home?

During that incident a girl, who was a complete stranger, yelled at the police officer to intervene, but even she was not willing to get directly involved. 
This led Bianca to reflect that, even though most people recognise that violence is wrong, a lot of people are too afraid to get involved. Frances and Dani also experienced this willingness by others to simply ignore the problem. They both felt that people preferred not to think about IPV too much, because otherwise they would have to look at the wider context in which violence occurs.

\section{Lack of understanding}

It was common for the women to feel that other people simply did not understand IPV. Four of the women reported that people they told seemed to be oblivious to the dynamics involved in abusive relationships. For instance, Dani stated that:

I don't think they do [understand how complex it is]. I don't even think my mum really - when I was little and she'd say, 'If a guy ever hits you just leave' - don't think she understood that it isn't just getting hit. It's a whole lot of other stuff as well.

Erica found that people were extremely open about their opinions that she should just not let her ex-partner treat her so badly, stating that:

People didn't understand the level of coercion that was going on...They just thought it was ridiculous and I needed to stop him doing that.

Once it became obvious that this was not working, people started attributing the abuse to the characteristics of the relationship itself:

People often tell you, 'Some people just don't get on, you know, this is a relationship thing, and you've got a bit in it and he's got a bit in it and it's all even Stevens'. And you'd believe that.

This lack of understanding extended to thinking that IPV is confined purely to physical acts. Frances reflected, "If I had been physically abused and been able to show bruises I think then I...would've got more help". The lack of understanding about IPV has continued to have an impact on how the women have been treated after the relationship, with Chloe explaining that she believes people do not understand. She stated that often she would be talking to someone about the abuse, but they would react in a way which suggested that they did not view it as an important issue. Erica elaborated 
further, explaining how the people that she disclosed to early in the relationship still viewed her in a negative light:

All that time friends and family are in a position of not understanding and getting really frustrated with you. And still [un]til this day [they] think that I'm a self-imposed victim and don't like [the fact] that I don't just get on with it.

While these were cases of family and friends making a conscious decision not to support the participants because they misunderstood the issue, there were also cases where people were trying to be helpful but ended up creating further harm. For instance, Frances described how people recognised that there was something wrong in the relationship, but tried to remain neutral:

People say, 'Well I don't want to take sides' but actually in doing that they've already taken a side. They don't seem to get that, you know? Because in not taking a side, you're actually taking the side of the perpetrator. 'Cause you're saying 'I'm doing nothing' and that means 'I'm doing nothing to help the victim'. And that supports the perpetrator the whole time. And I don't think people understand that.

Chloe also experienced people providing ineffective support because they did not understand IPV, talking about the one friend who she still had in common with her ex-husband:

She always comes and gossips [to] me about his life, or whatever, and I don't give a fuck at the moment. I don't really want to know. I just feel it's too rude, I know she tells me thinking she will help me and I'm interested. [But] I don't even know why because I don't care, I moved on, I have a complete different life.

The impression that Chloe had was that her friend thought it would be helpful to talk about the negative aspects of her ex-husband's life. But the result was actually that she annoyed Chloe who just wanted to move on from the experience.

Another common example of people not understanding IPV was the expectation that it should be obvious to everyone that the partner is abusive. Erica explained her frustration with this: 
People don't understand that the abusive partner doesn't walk around with 'abusive partner' written all over his forehead. And he's generally well liked and sociable and friendly, and the family quite often are...quite endeared by him. And so that 'There must be something wrong that you're doing' thing kicks in, because they expect, I don't know what do they expect? [Jake] the Muss ${ }^{12}$ or someone; someone that's going to be horrible the whole time? But they're very careful and very selective about when they reveal this stuff.

This was echoed by Frances and Annette, who both mentioned the fact that their ex-partners were perceived as nice, charismatic men. Because of this, Frances felt that people were much less willing to believe what she was saying and, instead, attributed what was happening to her own personality.

\section{Judgement and disbelief}

A number of the women felt that people were very judgemental of them.

Both Bianca and Dani reported that people judged them for staying in the relationship. Dani explained that:

People who just haven't really had an experience like that just don't get it... They'll pick at me for staying with a guy that's a really bad person.

Furthermore, Chloe and Frances felt that they were being judged as being the cause of the violence. When asked if she felt that people were judging her, Chloe's response was:

Oh yeah, definitely. Especially with my personality, I'm quite an outgoing kind of woman, so obviously it's like, 'Huh?' You know, that look of 'What have you done?'

This was also an issue that Frances faced, she explained:

If I could behave like a victim, I would get more support. But I just can't do it, I've always been independent, I've always been strong-willed, if you like. I just can't do that victim thing. And yeah, it goes against me again and again and again, because people think, 'Oh well, that can't be happening to her, she's stroppy enough'.

Frances went on to explain that she has been described as being 'highly strung', while there have also been times where she has got angry at her ex-

\footnotetext{
12 Jake the Muss was a character in the 1990 novel, and 1994 film, Once Were Warriors. His aggressive and abusive nature was a main feature of the storyline and is emblematic of family violence in New Zealand (Diederichs, 2005).
} 
partner's behaviour, leading people to judge her as "not credible, [and] not stable". These perceptions have led to a number of people rejecting her account in favour of that given by her ex-partner.

Disbelief was a very common theme in this study. Both Bianca and Chloe felt that people did not believe them about their experiences, while Erica explained this disbelief in more detail, saying that she expected her family and friends to believe her eventually:

When I finally called the Police and we went through that and I got the protection order, I thought people would understand. That they would see now that what I was trying to tell them was really real and really serious and it was really hard, but they didn't. And that was quite a shock, because I sort of expected the family to come back and support me and give me a hand.

Frances reflected on her own experience of not being believed, explaining that she felt many people did not want to believe her, because if they did they would have to examine their own lives. She believes that for many people it is easier "To pretend it doesn't exist”.

\section{Stigma of single motherhood}

For many women the fear of social stigma was a major factor when making a decision of whether to disclose the violence in their relationship or not. While there was a significant amount of stigma felt as a women who experienced IPV, this has been covered in the 'stereotypes and attitudes', and 'judgement and disbelief' sections above. However, there was another significant source of stigma felt by three of the women - the stigma of being a single mother. By the time they left the abusive relationship these women had children with their partners, and had to deal with bringing up these children by themselves. When asked whether she felt stigma at becoming a single mother, Erica responded:

Yeah, definitely. And I think that's part of your identity at that point, you're a married woman with kids and you suddenly turn into another thing. You go to WINZ [Work and Income New Zealand] and you're a single mum and you feel that stigma. 
This stigma was also felt by Dani. She described how she felt society treated survivors who needed to go on welfare after leaving their partner:

Women that have been in abusive relationships, when it comes time to [leave] they don't have lots of opportunities. Lots of them haven't been allowed to work or get an education and their life's been about raising kids and stuff. So when they leave they're quite often just going to have to go on the benefit for a while as a temporary thing, 'cause you can't live without money. And I think some of the attitudes that people have towards mothers, in particular, on the benefit is that they're bludgers. People kind of like to pretend that these people are just bludgers, [whereas] I think a lot of these women are actually women who have been in abusive relationships. Like people don't just decide to go and have babies on the benefit for a living.

Frances felt that this stigma was very prevalent. She listed a number of examples where she, or people she knew, encountered the stigma of single motherhood in a number of formal settings. For example, her friend, who is a successful lawyer, was judged by a number of other lawyers because she was a single mother. Additionally, she came across a newspaper advertisement for a radio interviewing position using single mothers as a stark contrast to the 'respectable' position of the Prime Minister. She went on to explain how she felt single mothers were perceived:

And there is [stigma], even though there are more and more relationships breaking up and there are more and more single parents, but yeah there is a stigma attached to it. And even, someone I know who was a single mother, but she's repartnered, she said that people are still afraid of her. Her friends are afraid she's going to take their husbands and the husbands don't want her hanging round 'cause she's now in a new relationship. And even the fact that she has been one, [when] she's no longer one.

After this Frances also described a number of informal settings in which she had felt stigma of being a single mother. For example, she had found that many people expected her children to be poorly behaved, purely because she was a single parent. Additionally, she experienced often being treated with suspicion if she took her children to an expensive hotel or restaurant, because it was expected that she should not be able to afford it. This is an 
important issue in relation to IPV, because this stigma makes it more difficult for mothers once they leave abusive relationships.

Imposing ideals upon the women

Most of the women reported that family and friends had ideals and expectations concerning what they should be doing about the abuse, which they would impose upon the participants. In relation to this, Bianca recalled an incident that her flatmates witnessed early on in her relationship:

The first time he ever did anything was not very long after he moved into my flat...And my flatmate actually confronted him at the time, and she told the other flatmate the next day and I remember her sort of shaking her head at me and being like 'I don't know why you're going to stay in this relationship, why are you doing this?' But other than that nothing was ever really said...Everybody else saying he's psycho and stuff didn't really make a lot of difference.

Bianca felt that her friends were willing to pass judgement on the situation, and tell her that she should not be staying, but at no stage were they willing to take any positive action to help ensure her safety. This was something also experienced by Erica. She felt that the only advice she ever received was concerned purely with her taking responsibility:

It was sort of all about me taking action, nobody else taking action to help and I wasn't in a space where I could be taking any action so then I just started to feel all this responsibility on my shoulders. 'YOU need to make the decision, YOU need to get yourself out, I don't know how you're going to, but YOU need to do this and YOU need to do that'.

Erica went on to explain that there was an expectation that after the relationship she should have been able to stop feeling down and get on with her life very quickly. However, she explained that this was something that took time and effort, and so these expectations were unrealistic. Both of these women were in difficult positions and expected people to help them; however, none of these people ever made any effort to provide support. Instead they passed judgement and told the women that it was their responsibility to change the situation, despite the women's positions of powerlessness. 
Bianca found that she and a friend of hers, who had also been abused, often encountered people who held strong views about what should be done by people who experience IPV:

She said to me that she was talking to somebody about it and they were just really derogatory, like 'Why would you stay? I'd do this if that happened, I'd do this and that' and all this sort of stuff. It's like, 'You wouldn't know what you'd do so don't just sit there and say you'd do this and you'd do that, because you have no idea. You don't know until you're in it and you don't know the dynamics of the relationship because, again, every relationship's different'...That's not happened to me, I haven't had that, I haven't had the 'I'd do this and I'd do that', 'cause you can't do that. But there's a lot of people who sort of think they know what they'd do. Because they see something...they make a comment about it, and it's never been about my specific thing but they do do it, they're like, 'Oh well, I wouldn't do that'. And it's like, 'Well, you wouldn't know'.

Bianca felt that people held views about how easy it should be to leave, similar to the attitudes held by Dani's mother (mentioned under 'stereotypes and attitudes'), which were not grounded in experience and were often not realistic given the amount of coercion involved in IPV.

While these were examples of external expectations during the relationship, more participants found that people imposed their ideals upon them after their relationships had ended. For instance, Annette found that her sisters had views about how she should be feeling about the situation:

I think that lots of people, you know my close family, my sisters, were very angry. And I think for a long time afterwards they were really frustrated about my lack of anger. And I remember my sister saying to me, 'When are you going to be angry?' And that wasn't particularly helpful; I didn't feel like it was going to be helpful for me to be angry.

For Annette, it was a case of being told how she should be reacting rather than being allowed to respond in a way that felt appropriate to her. Dani had a similar experience, feeling in many cases that her friends would not accept any decisions she made:

If I told my friends now, like if I suddenly decided I'm going to make up with this person and be together with him again, my 
friends would just instantly be like, 'You can't do this'. And I think everyone gets sick of being told what to do by people...I couldn't imagine any of my friends actually helping the situation.

\section{Effects of negative reactions}

Experiencing negative reactions from family and friends had major effects on the participants in this study. Most commonly, these reactions caused the women to stop talking about the abuse. When talking about her experience of reaching out to her ex-partner's brother-in-law who subsequently ignored her (discussed under 'withdrawal and ignoring'), Annette stated that she never asked for help again until the relationship was over. Annette went on to say that she thought that the outcome of her relationship could have been much more positive if he had met up with her. Chloe described this in more detail, explaining the effect of people coming across as indifferent to the abuse:

And [they say], 'Oh yeah, whatever', so that makes you just go backwards. I mean, if you're not going to give this the importance it has, because first of all it's really hard to realise that it is important... When you realise it is important and you start talking about it and people don't give it the same importance, I think that's the main reason why you just don't talk about it then.

Similarly, the reactions Dani experienced made her decide to stop talking to her friends about the abuse. She explained:

I don't really bother telling my friends 'cause they all just tell me what to do and that's really easy to say what someone should do and it's different to actually do it. So I don't bother with my friends.

Erica explained that her reason for ceasing disclosure was that she was "getting that slap-back", where more problems arose when she acted on the advice she was given. This showed that it is important not to ignore the effects of such enforced silence, as it has the effect of preventing women who experience IPV from seeking and accessing positive support. 
For Erica and Frances, the lack of support they received served to isolate them further. This was something both women mentioned a number of times. For instance, Erica explained:

I got really isolated. My family, in particular, didn't want to hear about it anymore. I was upsetting them with telling them what was going on. And then I felt responsible that I was causing them stress, and they just couldn't deal with it. They basically just told me they couldn't deal with it and they didn't want to know anymore...Yeah, [I was] really, really isolated, which made it all worse.

Erica further described how this isolation was much worse at particular times of year, and that she was confused by why she was in such a situation:

It's those Christmas times, and it's the fact that your family doesn't come back to you...So to this day I still don't see them, or no contact on Christmas. It's just me and the boys ...And yet [I] think, you know, 'What'd I do? Someone tell me what I did'.

Both Erica and Frances felt as though the people that they disclosed to had punished them for their ex-partners' actions. These women were the participants who received the least support, and the isolating effects of that were still clearly present.

Experiencing unsupportive reactions also caused a number of negative emotions for the participants in this study. For instance, Erica reported how the insistence that she take action by those she disclosed to made her feel as though she was going crazy:

You'd be always working on what you could fix 'cause you thought there was something that you were doing stark raving mad.

This was something that Chloe also felt, explaining that she had to move on from this:

You just end up trying not to give a fuck about it [judgement]. I mean otherwise it drives you nuts...Like heaps of times the topic of violence comes up and people ask and you get funny looks.

These negative reactions also led to anger amongst the participants. This was most prevalent for Dani, who was frustrated by the naïve advice and opinions her friends gave her. She also explained this in relation to her mother, saying that when her mother disagreed with her about something, 
she would get angry and defensive about it. For the most part she reported her mother's actions as being helpful, but this statement made it clear that even some of her actions were problematic.

\section{Positive Reactions}

This section brings together the participants' responses to questions such as 'What actions were helpful?'; 'Did you feel supported?'; and 'How did this influence your actions?' to examine the positive reactions to disclosure and the effects of these actions. It begins by discussing non-judgemental listening, before examining family and friends' understanding of IPV, followed by the way in which family and friends empowered the women, and the tangible support that some women received. This section concludes by discussing the effects of receiving these positive responses on the women.

While all of the participants had some negative experiences, there were also a number of positive experiences. Annette, Bianca and Chloe described their overall experiences as being mostly positive, while Dani described the support she received from her mother as being mostly positive.

Non-Judgemental listening

One of the most common positive experiences that the women described was when people listened non-judgementally to what they had to say. As Annette explained:

I think probably the main thing is just listening. Because, I was at a point where I didn't want anything to happen, I didn't want to press charges for any of the incidences, I didn't want to have anything to do with him...I certainly wasn't looking for solutions, I just wanted to off-load.

This was something that Annette brought up a number of times in her interview, and a point that Bianca agreed on. Bianca explained that, even at the time of the interview, people listening and giving her the opportunity to talk things through was very important: 
I was talking with my friends over the weekend, we were kind of like, 'Oh, fucking [ex-partner], he did this and that'. And my friend was like, 'Oh fuck, well that's not fucking okay is it?' kind of thing. And I was like, 'Well na, blah, blah, blah' and then we just moved on.

Chloe and Dani also touched upon the importance of listening, explaining that when people listened to them, it made their experiences much easier to handle. Frances summed up just how important this really was:

I have a best friend that I've had for years...and I speak to her pretty much every day and she has been my huge support. I mean she's family, friend, everything, you know? If I didn't have that I just don't know how I would've survived and got through.

These statements show that being given the opportunity to talk through these issues with someone had a significant impact on the women's ability to cope with their experiences.

\section{Understanding}

Erica said that among the most important reactions she received were ones which emphasised "belief and understanding”. This was also important to a number of the other women. For instance, Chloe said that, while there were a lot of people who did not understand IPV, it made a big difference when someone offered support and made an effort to understand. While most of the women reported instances when people did not understand what was going on, it was clear that instances when people did understand had a significant impact. Furthermore, people helping them to better understand their situation also helped them, as Dani explained:

[Mum] not just listened but sometimes shared her views on domestic violence and stuff.... When she shared some of the stuff that she either knows or her opinions about domestic violence sometimes it's helped me, kind of, understand the relationship. Because for a long time I didn't realise [that] this person had a whole lot of power and control and then I didn't have any. So yeah, sometimes her views, she'd share them and that would help.

While for many of the women there was a fine line between people imposing their opinions on them and helping them to understand the abuse, when people managed to get the balance right it had a very positive effect. 
A recurring theme when talking about understanding was how important shared experience was. As Frances stated, women who had experienced abuse similar to her own were often the women that she formed the strongest friendships with. She went on to explain that this was:

'Cause they absolutely understand, you don't even have to, you know, you're being believed straightaway and they've got no reason to want to disbelieve you.

Both Dani and Chloe agreed with this, with Chloe stating that similar experiences made it easier for people to understand the situation. Erica elaborated on this further, talking about the women she made friends with through her Women's Refuge group:

There's a level of understanding, you know, they get you. And you form quite a quick bond because you start telling stories and the person next to you is going, 'But that's what used to happen to me'...And you think, 'Oh my god, it wasn't just me, it wasn't what I was doing'...So that was quite good to find that stuff out and have that friendship of people that have been through it to do that.

Clearly, having people around who knew what they were going through was very important for all of these women, and the understanding gained aided them in being able to move forward with their lives.

\section{Empowerment}

For Bianca and Dani, it was important that they were empowered to make their own decisions. Bianca realised that she may not have always made the right choices, but she found that it was important that she came to that conclusion on her own. She used the analogy of a red button that could have serious consequences if pushed:

You have to figure out your own way, yeah. 'Cause it's like anybody telling you what to do...You just have to do your own thing and you've kind of got to work out that, 'Actually no, don't push the red button, 'cause you might find that something else bad happens' or whatever. And it's kind of like that...I'd actually be, probably, really pissed off [if] someone got involved in my shit. 
It was the same for Dani; her mother discovered very quickly that letting

Dani make her own decisions was important:

Mum has always said that she never bothered trying to convince me that it was a bad relationship because she thought it was something I needed to learn on my own. Because she thought that if she tried to break me away from that relationship it would cause more friction between me and her and it might be better to just stick by me so I had someone to turn to when things did get bad.

By being able to come to their own conclusions and make their own decisions, they were able to regain some of the power that had been taken away from them during their relationships. For these women this was a major step in being able to move forward.

\section{Tangible support}

Half of the women talked about the usefulness of more tangible forms of support. Chloe described how, when she went back to South America soon after she ended her marriage, her friends started going out of their way to help her, often coming over and doing things such as cooking for her:

I think I was quite fragile, I'm not a fragile kind of woman but in that period I was. And so they treated me more delicate, like I was saying that they spoiled me and they gave me time. But I think they gave me more protection than usual.

She said that her friends were apologetic for not being there to support her earlier, and did everything they could to make up for it. For Dani, being a single mother and a beneficiary made it very difficult for her to manage financially. Her benefit did not cover all of her expenses, so she was fortunate that her mother assisted her financially. When she first left the relationship there were also a number of practical things she needed assistance with. She explained:

My mum helped me in regards to taking me to all the places I needed to go to get a protection order, like to a lawyer...Mum's been really supportive in not letting him bully me into getting an abortion and stuff like that.

The most tangible support that Erica received was from a couple who took a definitive stand to support her: 
There's only one couple that really stayed in contact with me and they've been really good. And they just took a very strong stand right from the beginning, particularly the woman in the couple. She just didn't agree with what he was doing, [she] could see what he was doing. And we were very close, so she knew my kids really well and she could see the impact on them. So she's a very strong woman who just said, 'I want nothing to do with him and we will support you' and told him that, 'We are supporting Erica'. And that was like, 'Wow, really?' But that was only one person, but it was very important, really important.

However, Erica felt that there was a lot more that needed to be done to support women who experience IPV. She felt that modern society lacks a sense of community, and referenced the White Ribbon Campaign ${ }^{13}$ in explaining that most of society's responses to IPV are purely symbolic:

I know they do the motorbike things and they wear the white ribbons but, you know, what you actually need is someone to turn up with a casserole or to maybe mow the lawn or just to say, 'I know you and we care about you and we know you've gone through this'.

She felt that this sort of practical support would have helped her at the stage when she had just left her ex-partner, and was feeling depressed and struggling to get out of bed each day.

\section{Effects of positive reactions}

One of the biggest effects of positive reactions was that the women managed to gain an understanding of what had happened to them. Bianca explained:

I spent six years of my life thinking to myself 'Oh, it's not that bad, this is just normal. This is not that bad, this is just the shit that happens'. And when I actually say it people are like, 'What? He did that?' and I'm like, 'Crap, it actually sounds really bad when you actually put it out there'...That's actually been a learning thing for me, 'cause other people have to say, they're like, 'What? Really? How could you stay?' and all this stuff and you just do, you just do, that's just life.

This was something that Dani also experienced, reporting that she was surprised at how easily other people could see what had been happening.

\footnotetext{
${ }^{13}$ The White Ribbon Campaign is a campaign in which men wear white ribbons on the $25^{\text {th }}$ of November and vow never to use violence against women (White Ribbon Campaign, n.d.). As part of this campaign in New Zealand there is an annual motorcycle ride around New Zealand in order to spread the message.
} 
She said that until recently she had not understood the dynamics involved in a violent relationship, and so had not been able to effectively identify the abuse.

The women explained that leaving the relationship, and gaining support and reassurance from those they disclosed to, was a source of strength for them. As Annette said:

It really helped the way that I was able to frame that relationship...I think, because I didn't feel any of the stigma attached to it, I felt stronger for leaving and it was all good things, I think, at the end of that relationship, as opposed to bad.

This feeling of strength, which was apparent to some extent in all of the women and will be discussed further in the following chapter, helped the women move forward with their lives and view their previous experiences in a more positive light.

\section{Summary}

All of the women in this study mentioned that there were people who knew about the violence but never said anything to them about it. This is consistent with Fanslow and Robinson's (2010, p. 943) study, which finds that 40 per cent of women who experience IPV report no external support. Some of the women in this study felt that this silence was due to IPV making people uncomfortable, which is supported by Davis and Brickman's (1996) findings. Other women thought that people wanted to do something about the abuse, but did not know how to approach it, while a further group were concerned about upsetting the women by getting involved. These findings are also consistent with the literature, with both McLaren (2010), and Metzger and Woodley (2010) reaching similar conclusions.

Another barrier to disclosure that was commonly reported was societal attitudes and stereotypes. A number of women mentioned the stereotype of those involved in abusive relationships being from a lower income and ethnic minority background making it more difficult for them to disclose. 
This is supported by a number of studies which suggest that blame is often removed from upper-class white males, while simultaneously more blame is placed on women who do not fit stereotypes (Black, 2011; Larcombe, 2002; McManus, 2005; Skelton \& Burkhart, 1980). Furthermore, participants talked of people holding attitudes that women were to blame for staying in abusive relationships and that women did not want people interfering. These feelings are reflected in the literature, which reports people feeling that women could leave if they wanted to and, therefore, are equally responsible, and that IPV is a private matter that others should stay out of (Bui, 2003; Flood \& Pease, 2009; McLaren, 2010; Sullivan, et al., 1992; Taylor \& Sorenson, 2005).

Two of the women described how their partners isolated them from potential forms of support, and explained that this made it more difficult for them to disclose. Giles et al. (2005) and Kearney (2001) report that isolation is a common tactic used by abusive partners, while other studies report that this isolation is a major barrier to women disclosing (Fugate, et al., 2005; Sudderth, et al., 2009). Finally, two women reported that their previous experiences influenced their support-seeking decisions, which is consistent with Fanslow and Robinson's (2010) finding that support throughout a relationship makes women more likely to disclose abuse.

When the women did disclose, they often received unsupportive reactions. Some of the women reported that the people they disclosed to withdrew from them and remained silent, which is consistent with Fanslow and Robinson's (2010) finding that more than one-third of women who seek help do not receive it. Additionally, a number of women reported that the people to whom they disclosed lacked an understanding of IPV. This is in line with findings that people do not view IPV as problematic (Fanslow \& Robinson, 2010) and that "People hold inappropriate conceptions about what is and is not helpful for those experiencing traumatic events" (Kaniasty \& Norris, 1992, p. 233). Such findings lead Metzger and Woodley (2010) to conclude 
that the majority of unhelpful responses result from people who do not understand the complexities of IPV.

Most of the women reported being judged by some of the people they disclosed to. This is consistent with Giles et al.’s (2005; See also: Kingi \& Jordan, 2009; Moe, 2007) finding that women often have experiences of being blamed for the violence against them, and Metzger and Woodley's (2010) finding that many women experience judgement and disbelief. A number of studies find that when women are not seen as passive victims, and are instead seen as "stroppy" or "breaking his balls" (Towns \& Adams, 2009, p. 743), or as acting in a provocative manner, they are much more likely to be blamed (Leisenring, 2006; Taylor \& Sorenson, 2005; Towns \& Adams, 2009; West \& Wandrei, 2002; Witte, et al., 2006). Furthermore, Fields (2008, p. 97), states that:

[Many] victims of IPV may appear less stable than their violent partners because they are suffering from the emotional effects of abuse.

This can greatly influence other people's opinions. These findings are consistent with this study.

Three of the women in this study had children with their former partners, and so became single mothers upon leaving the relationship. They found that there was a large amount of societal stigma directed at them because of this. Towns and Adams (2009) report similar findings to this, stating that women on their own are commonly viewed as inadequate parents. Furthermore, other studies note that mothers who receive welfare, such as the Domestic Purposes Benefit, are looked down on due to perceived laziness (Giles, et al., 2005). This disregards the fact that they are in that position due to the economic disadvantage caused by ending their relationship (Giles, et al., 2005; Leisenring, 2006; Reynolds \& Wetherell, 2003; Seecombe, James, \& Walters, 1998). Kearney (2001) offers an explanation for this stigma, stating that women are often given most of the responsibility for making sure a relationship works and are, therefore, to blame if their relationship fails. 
The participants in this study reported that their family and friends imposed their own ideals and expectations about what they should do about their situations. This is consistent with the wider literature, with many studies reporting that women who experience violence find it unhelpful when the people they disclose to attempt to define their situation for them and give excessive amounts of advice (Lempert, 1997; Mahlstedt \& Keeny, 1993; McDermott \& Garofalo, 2004; Metzger \& Woodley, 2010). Two participants found that when other people learned of the abuse, they instructed them to take action, placing all of the responsibility upon them as individuals. This is similar to a number of studies which find that people believe women who experience IPV should take self-protective action as soon as harm occurs and, therefore, only offer support on the precondition that women leave (Davis \& Brickman, 1996; Lempert, 1997; Moe, 2007; Taylor \& Sorenson, 2005). Such beliefs are problematic because they ignore many of the structural factors involved with the relationship and assume that others know what is best for the woman (McDermott \& Garofalo, 2004; Metzger \& Woodley, 2010; Rusbult \& Martz, 1995). This suggests that the woman's actions were not the most appropriate ones to take and, therefore, apportions some of the blame to the woman, while simultaneously disempowering her in the same way as her partner often has (Fanslow \& Robinson, 2010; Mahlstedt \& Keeny, 1993; McDermott \& Garofalo, 2004; Metzger \& Woodley, 2010).

The participants of this study reported that negative reactions caused them to cease disclosing, and isolated them further. This is supported by Metzger and Woodley (2010, p. 15), who claim that a lack of support creates a climate of tolerance, which "can drive the violent behaviour further underground and discourage the victim...from seeking further help". Additionally, it is argued that blaming and criticising a women who experiences IPV acts as a barrier to further disclosure (Carlson, 1997; Giles, et al., 2005). By putting in place further barriers to disclosure, it becomes 
more difficult for women to seek help and the problems caused by IPV are often exacerbated.

One of the most important forms of support for the women in this study was listening. This is consistent with studies which report that non-judgemental listening is experienced as positive by most women who have lived with violence (Gerbert, et al., 2000; Kingi \& Jordan, 2009; Mahlstedt \& Keeny, 1993; Metzger \& Woodley, 2010). This has been found to be particularly helpful when friends and family act as a 'sounding board' for ideas, as it gives women a sense of validation of their own self-worth, and experience and knowledge (Fanslow \& Robinson, 2010; Gerbert, et al., 2000).

Another form of support that many women found helpful was when the people they told properly understood IPV, especially when these people helped them to understand their situation. This is supported by a number of studies which find that one of the most effective forms of support for women who experience violence is unconditional informational support, in which family and friends help them to understand their situation (Clements \& Ogle, 2009; Kaniasty \& Norris, 1992; Kingi \& Jordan, 2009; Lempert, 1997; Metzger \& Woodley, 2010; Moe, 2007; Sudderth, et al., 2009; Waldrop \& Resick, 2004). Further studies claim that this is particularly the case when supporters name the abuse and help the women to review their definitions and views surrounding violence (Gerbert, et al., 2000; Lempert, 1997; Metzger \& Woodley, 2010). Lempert (1997, p. 300) explains that this must be "definitional assistance not definitional oppression", which is consistent with one woman's account of her mother helping her to reinterpret the situation. Similarly, two women found it to be very important that they were empowered to make their own decisions around what actions to take. This is consistent with a number of other studies which report that it is crucial that family and friends provide assistance so that women can arrive at their own decisions, and that they support those decisions 
unconditionally (Lempert, 1997; Mahlstedt \& Keeny, 1993; Metzger \& Woodley, 2010).

Half of the women also reported that it was particularly helpful when those they disclosed to offered them tangible forms of support. This is consistent with a large body of literature which finds that providing shelter, financial resources and childcare are often some of the most important things that family and friends can provide for those who have experienced violence (Kingi \& Jordan, 2009; Metzger \& Woodley, 2010; Postmus, et al., 2009; Sullivan, et al., 1992). It is noted that the reason this is so important is that many women, particularly those in abusive relationships, are financially dependent on their partners. As such, providing tangible support assists them in becoming independent (Dichter \& Rhodes, 2011; Ferraro \& Johnson, 1983; Strube \& Barbour, 1983). The tangible support received by one woman was in the form of some mutual friends making it clear that they were supporting her and speaking out against her ex-partner's actions. Ferraro and Johnson (1983) report similar findings, claiming that outright condemnation of a partner's actions is extremely important.

The women in this study reported that the positive support they gained helped them to develop a better understanding of IPV. This is consistent with literature which argues that positive support helps women to reevaluate their situations (Metzger \& Woodley, 2010; Sudderth, et al., 2009; Waldrop \& Resick, 2004). Furthermore, this re-evaluation leads to greater confidence and a greater likelihood of continuing to seek help in future situations (Fanslow \& Robinson, 2010; Metzger \& Woodley, 2010; Sudderth, et al., 2009). This is largely consistent with the accounts of women in this study, who reported increased strength and empowerment as a result of their positive disclosure experiences, while the majority of the women continue to seek ongoing support. This will be discussed in the following chapter. 
The Social Factors reported in this chapter significantly interacted with the Personal Factors and Recent Factors reported in the other analysis chapters. The stereotypes and attitudes, and lack of understanding mentioned in this chapter come from a similar source as some of the reasons for not disclosing, mentioned in the third chapter. It will be shown in the following chapter that the women reflected that information about IPV was not readily available to the public, explaining this reliance on stereotyping and many people's lack of understanding. Furthermore, many of the negative reactions received upon disclosure were due to the fact that family and friends were unaware of the dynamics surrounding IPV. 


\section{Chapter 5: Recent Factors - Ongoing Support, Reflections and Observations}

\section{Introduction}

This chapter focuses on the varied factors of ongoing support, reflections and observations. While this chapter could be seen piecemeal collection of the remaining issues not discussed in the previous two chapters, I would describe it as an indication of where the women are at when the interviews took place. The first section in this chapter examines the ongoing support received by the women. This is followed by an examination of the reflections that the women had on a range of factors, including the relationships themselves and the availability of information surrounding Intimate Partner Violence (IPV). Then this chapter will focus on observations I made while conducting the interviews, including the way in which the women depersonalised their former partners and the way in which the participants were not passive victims, but strong survivors. The chapter concludes with a comparison to the wider literature, showing that many of the findings in this chapter are, in fact, reasonably common.

\section{Ongoing Support}

This first section examines ongoing support, based on the women's responses to the question 'Do you have ongoing support?' Much of the information in this section relates to friendships formed through Women's Refuge (Refuge), due to their greater understanding of IPV.

Many of the women in this study continued to receive ongoing support from various sources. Annette, Bianca and Chloe all worked or volunteered at Refuge, while Dani and Erica had been involved in Refuge support groups. The connections formed there made up one of the women's major sources of support. Annette explained the accessibility of support, saying that because she worked in the IPV field she had access to any help she required. Both Bianca and Chloe found that the support received from their Refuge colleagues was extremely important, particularly as many of them had 
experienced similar relationships. They likened this support to counselling, with Chloe stating:

I think now it's different because I work with Women's Refuge and I'm in constant contact with victims, with ex-victims and that. So you've got a complete different understanding and you've got people that...have shared [the] same experiences so it's really, it is a massive support for me. Doing Women's Refuge is kind of like therapy for me, I have done it for near two years and I think it's that reminder of not going back...And also I think there is no-one that understands you better than someone that has had the same experience.

Bianca explained that starting to work at Refuge was part of her process of dealing with her issues and moving on with her life:

It's only since...we broke up in the last three years that I've started working with people who are still in violent relationships. And I sort of did that because I realised that I hadn't really dealt with a lot of the stuff that happened, and I was kind of like 'okay I really need to do something about this'...So I did a whole lot of courses, like personal courses, and I see a counsellor and all that stuff and I also work for Women's Refuge.

For Dani and Erica, the contacts made through their Refuge support groups were important in helping them deal with their experiences. However, Erica found that this was only helpful for a limited amount of time:

I made friends with that group from the women's programme, but that sort of had a lifespan of its own as well, and that got to a point where it was better for all of us to move away from that group, because we were sort of keeping each other in that space. Like it was really important, but I think it has a, you know? [It's something you've got to move on from?] Yeah. 'Cause it's intense talking about what's happened, and there's got to be a time when you talk about what you want to do next.

While the support they gained from their involvement with Refuge was important for them, the fact that they were helping other people was also vitally important for Bianca and Chloe. As Bianca explained, "[I] decided if I could do something, just to even help one person, then that's enough for $m e$ ". However, there was a significant difference in how these two women 
approached this task of supporting people. Chloe felt that there was no reason for her to talk to clients about her own experiences:

I don't usually tell them. I know, for example, the people I work alongside; yes I think most of them know...you just end up talking about it. But with clients, no - I'm there to support them and sometimes I understand what [they're] going through, but [it's] that kind of support. I think the support comes from the people [who] have lived the same thing as me, and now that we work alongside each other.

In contrast, Bianca felt that telling clients was an important part of helping them understand IPV:

You're telling them as a learning thing...The thing with me is that I've learnt that it can happen with anybody, it doesn't just happen to one kind of person, obviously. A lot of the women that we work with at refuge, they're like, 'It happened to you?' 'Cause they're like, 'Why do you work at Refuge?' and I tell them because it happened to me. And [they say], 'It happened to you? But you're educated and you've got a job' and that sort of stuff, and it's like, 'Well yeah, it happens to everybody, anybody'. So, you know, I guess it's not finding vindication for what happened or anything like that, it's just sort of 'Yep this happened, you can deal with it'. It's not about them feeling sorry for you either, while it's great for them to understand and all that sort of stuff, and sort of see that you can actually survive it. To me it's more like I'm telling them so it doesn't happen to them.

Bianca later stated that the reason she disclosed to clients was because of communication she had with the mother of a young woman who was killed by her former partner:

You know Lesley Elliott? Sophie Elliott's ${ }^{14}$ Mum, I wrote to her and I told her what had happened, 'cause she's got this foundation, the Sophie Elliott Foundation. I emailed her and said, 'Well if you ever need any help with it, please let me know'. And there's quite a few people that have obviously written to her and said the same sort of thing; she's got a list of these volunteers. Anyway, her message to me was 'If you have the chance, tell your story. Just tell everybody, 'cause the more people that know, hopefully, the less people this will happen to', kind of thing. And I think that's the sad thing is that still people don't want to talk about it.

\footnotetext{
${ }^{14}$ Sophie Elliott was a New Zealand woman who was murdered in 2008, aged 22, by her former boyfriend (The Sophie Elliott Foundation, n.d.).
} 
Bianca said that after this communication she had taken every opportunity to talk about her experience and let other people know what happened to her.

While ongoing support is important, Annette said that there was a specific reason she continued to talk to people at Refuge rather than others:

I suppose with close family members like my sisters, you kind of reach this point where you kind of feel like it's a bit boring, you know? You don't, kind of ,want to be going on about this all the time or to be dredging this back up over and over again, but there are certainly times where I feel like I need to talk this through again. And I don't know if I would do that with my close friends and family, I'd probably do it with people that I know through work. And that's just maybe because, I don't know, I suppose people think that you should be over it by now.

When asked whether her family and friends had ever said anything to cause her to worry about this, Annette responded:

Nah, no, I don't think that's fair. I think that that's just me being a martyr, maybe, and just not wanting to bore people, but even that sounds ridiculous. I don't know, I can never quite decide how big this is, do you know what I mean? Like, is this a big deal or am I just being self-indulgent? This all sounds ridiculous coming out of my mouth.

Erica reported similar fears about 'wearing out' friends by continually talking about her experience.

\section{Reflections}

This section discusses the women's reflections on their situation. Most of the information in this section did not come about through a specific, planned line of questioning; rather it came from the participants leading the interviews in these directions. The information within this section covers realisations about a range of issues. These include: the relationship itself; the women's framing of the relationship; the events after the relationship; and the availability of information about IPV. 


\section{The relationship}

For many of the women, there were things they wish they had done differently in their relationships. While Annette said that "I don't think I was doing anything consciously in terms of outcomes", if she could have her time again she would do a number of things differently. When asked what she would change, she said:

I wish that I had told [my family and friends] a lot earlier. I wish that I had, sort of, let people in and not tried to protect him and tried to protect us. I wish that I had known that they were going to be supportive and that they were going to be respectful about my privacy and not wanting to tell lots of people...I think that I just needed someone that I could say it out loud to so that I could at least hear it, because as soon as I start talking about these incidences now I just think, 'This is crazy, it's so crazy that it got to that level'. But I never really had the opportunity.

Since her relationship ended Bianca found out that her previous boyfriend had heard about the abuse, and considered going to her house to remove her from the situation. She stated that she was not sure what would have happened if he had done that, but gave the impression that if he had intervened she would have accepted the help.

For these women, it has only been since their relationships have ended that they realised the extent of the abuse. Bianca stated that it was only through the process of reflection that she realised how violent her ex-partner had been. She also realised that the relationship dynamics had been more like that of a mother and child rather than a healthy adult partnership. She went on to explain how surreal the situation seems now:

I laugh now because I'm just like, 'Oh my god, I can't believe I lived like this for so long'...And it's only sort of since he's gone and he's not here anymore that I'm kind of like, 'Oh shit, I've lived this whole thing' and I'm so tired and I've finally realised why. And [I've thought], 'Hang on, this whole thing's just been a nightmare' and then I've started to realise that 'Oh my god, I'm actually out of it. I don't have to deal with that anymore'. So it's just insane coming out of it. 
Frances experienced something similar, stating that she was not aware of the extent of her former partner's abusive behaviour until she reflected on it once some time had passed.

One of the factors in realising how bad the situation had been was other people's reactions. Bianca explained how she went from trying to rationalise the situation, to now realising how bad it actually was. As mentioned in chapter three, she spent the entire period of her relationship thinking that what she was experiencing was normal, but when she has talked about it since she has realised how bad it actually was. She pointed out that, even at the time of the interview, "Objectively I can see that it was that bad, but subjectively I'm kind of like 'Well I survived so it can't be that bad'”, which is something she was battling to overcome. While Bianca's realisation came through talking to family and friends, for Dani it came through formal court proceedings:

Last week...he pleaded not guilty to Threatening to Kill or Do Grievous Bodily Harm and he pleaded not guilty to Contravening the Protection Order and Breaching Bail and all these other things. And I got really upset and it was just after my women's group thing and I was at the Women's Refuge...And I don't know why I got so upset, so I was sitting down talking about it to one of the other advocates... and I realised for the first time how actually messed up everything actually is. So it's only like really, really recently. I've always known things were bad, but it's only recently that I realised kind of how bad things are. And...I've got [text] messages and I read them and I was just like finally seeing [that]...I guess I got desensitised to a lot of the abusive stuff and I was just realising how abusive he is. And then even today I got a letter from the court [which] has basically granted me full custody of my son...I was reading the judge's reasons and I was just like 'I can't believe other people see it so easily', 'cause I didn't.

That these women were unable to recognise the seriousness of what was going on for so long illustrates the importance of having an outsider's perspective on their situations. By incorporating the perspectives of outsiders, participants were able to overcome their own subjective normalisation of the abuse and seek the help they required. 


\section{Framing their experience}

In looking back on the relationship, the participants framed their experiences in very different ways. For Annette, there was a feeling of anger that her ex-partner has not been held to account for his actions:

I often think that if I do [run into mutual friends] and we were having a conversation about why the relationship ended, is now the time to be honest? Or should I not be honest? And is that just still protecting him? And why am I doing that? And is there something that's stopping me? I mean, at times I get really angry and I just think it's so unfair that he is really untouched by this...[He] has no sense of accountability or responsibility... and the unfairness of that makes me angry. And part of me is like, 'Well I should tell people, 'cause he's an arsehole'.

On the other hand, Bianca and Chloe both tried to look at things from a more positive perspective. They saw their experience as something they survived and learned from, making them stronger. Both of them made it clear that they did not want to forget the experience; instead they acknowledged that it was a major part of who they were:

You know, funnily enough I look back and, yeah, there's parts of the relationship that makes me really sad, because I still wish that he was different to what he is now. But I wouldn't change it; I wouldn't change it, because how much have I learnt from going through it? And now at least I can actually understand when I help these people [Bianca].

[Dad said,] 'Oh why don't you get your marriage annulled?' and I said, 'Nah'. I mean, I did marry him so I'm going to annul thus it never happened - it did, it happened. So let's live with it and move on rather than 'Ah it didn't happen', you know?...[My family] helped me get through it. My sister, I was whinging about all the money that my ex-husband cost me, and she was like, 'How much does your freedom cost?' That's a positive way to look at it, and I think people helped that way, you know, just finding the positive things to it [Chloe].

On a related point, Bianca made it clear that she did not view herself as either a victim or a survivor; instead she viewed it as just another life experience - like travelling abroad. However, she was pleased that she had left it behind. 
Events after the relationship

The women also reflected on events after their relationships had ended. For instance, Erica reported how things in her life seemed much more positive after she left, explaining that:

The world started opening up, there's strange things. You didn't notice that your world becomes very narrow because you're so busy managing the violence all the time that you're just surviving day to day. And you get into that space and someone explains it to you and suddenly you're driving down a road that you've driven down, maybe, a million times dropping your kids off to school and suddenly you see a tree on the top of a hill that you never knew was there, 'cause you've never actually looked up. Do you know what I mean? [There's more to life] than just this self-consuming thing.

Since her relationship ended, Bianca learnt to have a much more positive outlook on the way she reacted to her experiences:

What I'm kind of learning is that it doesn't actually matter how you feel, whatever you're feeling's actually okay. I can feel shitty, I can feel upset, I can feel hysterical, whatever and that's how you feel. You can't help how you feel.

However, not all of the realisations that these women came to were positive. For instance, Erica felt isolated because of the events of her relationship, and recently had a reminder of her change of marital status:

I was thinking the other day, you know you go to your doctor's room, and they did an update form, and that's one of the things I hate is like all the medical stuff. They always say like, 'next of kin', 'contact person', 'who would we contact?' and I just go, 'blank', you know? Or if you've got a test that you have to do at the hospital and you've got to go by yourself, and you sit there and you look around and everyone's got someone with them and [you] think, 'This is shit' - that's the worst times.

Erica went on to explain why she believed she continued to be so isolated after the relationship:

I think what happens, once you've gone through that period of being so isolated, is that you're always cautious going forward. And so, you don't tend to make close ties because [of] the idea of losing more people.

Dani found that many of her friends were not supportive throughout her experience and, looking back, offered a partial explanation as to why: 
I feel like, 'cause I've got a baby now and all my friends don't, I feel like I've, I don't know if grown up is the right word, but just kind of matured in different ways. So I don't relate to my peers as much as I used to. But when I was younger I definitely used to talk about it more and as I've got a little bit older I pick who I talk to about it. I pick more supportive people.

These perspectives highlight the fact that the women are still constantly learning more about, and gaining a greater understanding of, their abusive relationships.

\section{Availability of information}

Something that was commonly mentioned by the women was that information about IPV was not readily available to the public, making it difficult for many women to realise that the behaviours exhibited by their partners were abusive. Erica described how she had to seek formal support before she was able to realise the extent of the abuse:

It's not [un]til you go to a specialist agency where someone sits you down and knows, and gives you a list, 'Have you experienced this, this and this?' and you get down the list and go, 'Oh my god I've ticked all 20'. And they go, 'Well, this is what's been happening to you' and you go, 'Really?'

Erica later went on to explain that because her ex-partner was blaming their relationship problems on her, she needed someone to convince her that she was actually experiencing IPV. She emphasised that this was difficult to do without available information. In her mind, the public awareness campaigns being run on the subject of IPV do not provide enough information of this kind:

It would've been helpful if information about this sort of thing is more accessible to everybody, to victims that are going through it and to family and friends that are supporting. Because it feels like it's hidden away under lock and key, it's not out there. I know they're trying to do their public awareness campaigns but for me and for others who look at it, we go, 'Well, that doesn't reflect us' and I don't know if it tells anybody what it actually is....You've got to go a long way.

Dani agreed with her on this point, saying:

Even on those 'It's Not OK' ads...I was just thinking, it kind of needs to go further than just TV campaigns, 'cause I sometimes 
think that people in abusive relationships don't actually realise that they're in abusive relationships.

For both Dani and Bianca, one of the consequences of the lack of availability of information about IPV was that they held a stereotype of who is victimised, and because they did not fit that stereotype they did not recognise that they were experiencing IPV. As Dani mentioned in chapter three, all of her experience with IPV came from what she had seen in the media, which she felt had a strong emphasis on Māori women. Because of this, she did not initially realise that what she was experiencing was abuse, so realising that anyone can be victimised had been a major learning experience for her.

Three of the women suggested that a way to make people more informed about IPV could be through relationship education in school, similar to sex education. Bianca, Dani and Frances believed that this was vitally important because many young people do not know what is normal in a relationship, particularly if they have not had the opportunity to witness a healthy, functioning relationship between their parents. As Bianca stated:

I think one of my big pet peeves is that nobody is educated on this stuff when they're in high school. We get sex education and all that sort of stuff but we don't get 'This is not okay and you shouldn't have a relationship like this and this is what a good relationship looks like'...I always wonder whether or not if I'd been a little bit more educated on what a good relationship looked like [things would have been different]...I think people should get educated on it early...in the teenage years.

For Frances, education around issues such as IPV was far more important than some of the things that are commonly taught in school:

I would love to see that start in school. It's too late by the time you've become my age and had kids, it's too late. You need to learn about this stuff in school, I mean why learn about Pythagoras's theorem for god's sake? Learn about healthy relationships, you know?

Frances added that she felt it was important for survivors of IPV to go and talk to students, and that positive relationships should be emphasised to 
students so they have an idea of what a healthy relationship should look like:

There needs to be far more people come forward and speak out about it. There needs to be people like me going into schools and actually talking to people so that they can actually understand what it's like. But also there needs to be education for young men, young boys and young girls...about what is healthy and what is acceptable and what kind of future we want to create for our kids and all that kind of positive stuff. You know, and even at school I've said, 'Instead of doing antibullying, could we do promoting friendship?'

The fact that education was something that was mentioned by half of the participants suggests that it is an initiative that is worthy of investigation. As such, it will be discussed in further detail during the concluding chapter.

\section{Observations}

This section examines a number of interesting observations noted about the women during the interviews. The information presented here did not come about through any line of questioning, rather through noticing interesting patterns in the way the women talked about their situations. The way in which the women depersonalised their former partners will be discussed, followed by an examination of the way the women presented themselves as strong survivors.

\section{Depersonalisation}

One interesting observation was the way in which participants depersonalised their ex-partners. Half of the women never mentioned their former partner's name; although Bianca referred to her ex-partner by name the majority of the time. The women's former partners' names were often replaced by terms such as 'my ex-partner'; 'this person’; 'my son’s father'; and 'him'. In addition to replacing their former partners' names with more general terms, some of the women used very emotive terms in order to reinforce the negative aspects of their ex-partner. For instance, Annette described her former partner as 'an arsehole' and talked of 'his crazy behaviour'. Bianca also talked about her partner as being 'crazy' and 'a 
complete psychopath' whose actions were 'nuts', while Dani referred to her former partner as a 'really bad person'. This seemed to be an attempt to be viewed positively by comparison to their ex-partners, by portraying them as unlikeable people.

\section{Strong survivors}

Another observation was that none of the women presented themselves as passive victims, instead they all showed considerable strength and resilience. However, at times they seemed to feel the need to emphasise this fact. For instance, Bianca was very resistant to the label of 'victim', saying:

Yeah it's quite funny, 'cause I don't really see myself as one [a victim], I guess. And I guess people probably do look at me and they're like, 'Oh poor you' that sort of thing, and it's kind of like, 'Well, not really poor me actually', you know?

Bianca made a conscious decision that she was "not going to just sit here and be a victim", instead doing all she could to get on with her life. Similarly, Frances found that she was not able to act like a victim, explaining that "I've always been independent, I've always been strongwilled, if you like, I just can't do that victim thing". Chloe and Erica also made a number of comments emphasising their strength. This emphasis on strength was, in some cases, also accompanied by comments which portrayed a fear of being devalued. The following are examples of this from Annette and Bianca:

I think for a long time I had been successful in life and able to sort of manage my life and being the sort of key person in my family [Annette].

Because obviously I'm not stupid, I've got a good job, I've been to uni, I've done all that, I've got heaps of life experience, like all this sort of stuff, and I'm a functioning human being, like I help other people, so I'm not a failure [Bianca].

The combination of needing to both emphasise their strength and discredit any negative perceptions suggests that strength was an important factor for these women when coping with the experience of IPV. 


\section{Summary}

Five of the women in this study used Refuge as a form of support at some stage throughout their experience. There was one participant who was still part of a Refuge support group, while three women currently held positions at Refuge. The ability to help other women who were experiencing abuse was something that assisted them in framing their experiences in a more positive light. This is consistent with Ferraro and Johnson's (1983) findings that many survivors get involved with victims' organisations so they can help others and feel better about themselves for doing so. These findings can also be applied to one woman's position as an advocate for victims and survivors with another organisation.

Among their reflections, the women in this study discussed the process of moving on with their lives. They discussed their ability to reframe their experience in a more positive light so that they could move on, learn and grow. This is consistent with findings that once women have completely left their abusive relationships, they are able to give sense and meaning to what happened and, as a result, dramatic personal growth occurs (Giles, et al., 2005; Kearney, 2001). In addition to this, one woman described her anger at her ex-partner's lack of accountability. Giles et al. (2005) report that this is common, as many perpetrators are unaffected and survivors come to perceive this as an injustice.

Half of the women in this study also reflected on the lack of availability of information around abusive relationships and, in particular, the fact that there is no education about IPV, and relationships more generally, in schools. This is consistent with a wide range of literature which reports that there is insufficient information available to dispel myths surrounding violence against women, and to provide advice on how to effectively provide support to those who are experiencing it (Black, 2011; Fanslow \& Robinson, 2010; Fugate, et al., 2005; Giles, et al., 2005; Mahlstedt \& Keeny, 1993; McLaren, 2010; Taylor \& Sorenson, 2005). Furthermore, the 
participants' desire to see schools teaching about relationships reflects Giles et al.’s (2005, p. 110; See also: Ministry of Social Development, 2002) statement that all young people need to be taught relationship skills "Such as skills for regulating strong feelings (including anger), negotiating interpersonal conflict, and recognising abuse”. Giles et al. (2005) argue that this would enable people to understand what is appropriate in relationships, as well as giving them the ability to accurately identify abusive behaviours and take appropriate actions.

There were two major observations that I made of the women in this study. The first was that they often depersonalised their ex-partners, which is something that Towns and Adams (2009, p. 742) also observe with one of their participants continually referring to her husband as "This guy". This behaviour was of particular interest as it parallels tactics used by perpetrators of IPV who often depersonalise their partners in the same way (Bancroft \& Silverman, 2002; Domestic Abuse Intervention Programs, 2011; Romito, 2008). However, the literature suggests that batterers depersonalise their partners because treating them as objects makes it easier for the batter to justify acts which would otherwise be contrary to their moral code (Bancroft \& Silverman, 2002; Romito, 2008; Zimbardo, 2007). It is unlikely that women depersonalise their former partners for the same reasons, rather it is suggested that they engage in depersonalisation to make it easier to put their experiences in the past. However, this subject requires further investigation. The second observation was that the women were not passive victims; they were strong survivors, with some of them actively rejecting the label of victim and attempting to portray themselves more favourably. This is consistent with a number of studies which find that accepting the label of victim means accepting a definition of weakness, powerlessness and passivity, which apportions some of the blame to those characteristics (Lamb, 1999; Leisenring, 2006; Lempert, 1997). These studies argue that by rejecting this label women are able to portray 
themselves as active agents with control over themselves and, as such, are able to avoid a significant amount of shame.

The Recent Factors reported by the women significantly interacted with the Personal Factors and Social Factors mentioned in the previous chapters. As already mentioned, the lack of information available had a significant impact on the perceptions and actions of the women, and their family and friends. Additionally, as these women continued to seek ongoing support, they continued the tactic, described in chapter three, of managing who they talked too, choosing people who engaged in more positive actions. Furthermore, in helping other people through their involvement at Refuge, some of the women were able to support women in ways that they found helpful throughout their own experiences. 


\section{Chapter 6: Conclusions}

\section{Introduction}

This study aimed to examine the dynamics surrounding survivors' disclosure of Intimate Partner Violence (IPV) to their family and friends. Semi-structured interviews were conducted with six women who had experienced IPV within the previous five years, but were no longer in the relationship. Using a methodology which incorporated grounded theory and feminist perspectives, the transcripts of these interviews were analysed and the data was sorted into three categories. These categories, which formed the basis of the analysis chapters of this study, were Personal Factors, Social Factors, and Recent Factors. The findings in these chapters are largely supported by a number of other studies, both international and from New Zealand, suggesting that the findings were not limited to the participants of this study. The main findings of these three chapters will be summarised below.

\section{Summary of Findings}

Personal factors: actions and thoughts

The examination of internal, personal factors began with a discussion of the actions taken by the women to manage their situations. Participants discussed their disclosure of IPV commenting on how they chose their confidants; the timing in which they disclosed the abuse; and their attempts to hide the abuse. Furthermore, there were a number of personal barriers impacting on their disclosure which the women reported, including not recognising that the relationship was abusive; expecting that their partner would change their behaviour; shame; and fear of disappointing others. Additionally, the women reported clear expectations for the disclosure, including a desire to vent their frustration; to gain a greater understanding; and to receive reassurance. These findings concur with other violence against women literature, in that there was widespread consistency between these women's experiences and those of others in similar situations. 
Social factors: barriers, reactions and effects

The second analysis chapter focused on the social influences surrounding the disclosure of IPV, starting with the social barriers to disclosure. Among these barriers were other people's silence; societal stereotypes and attitudes; isolation; and previous experiences. All of the women experienced some negative reactions upon disclosure, including experiences of other people withdrawing from and ignoring them; a lack of understanding; disbelief and judgement; stigma of single motherhood; and the imposition of ideals upon them. These negative reactions to participants' disclosure of IPV meant these women did not want to disclose further abuse, which caused further isolation and left them feeling as though they were going 'crazy'. However, there were also a number of positive reactions that the women received, including non-judgemental listening; understanding; empowerment; and tangible support. The women reported that these positive experiences had the effect of helping them to understand their situations and giving them a sense of strength. These findings were found to be greatly consistent with wider violence against women literature, with many other studies reporting women having similar experiences.

\section{Recent factors: ongoing support, reflections and observations}

The third and final analysis chapter focused on a number of different factors, which indicate where the women were at in their lives at the time of the interview. The chapter began by examining the ongoing support that the women were receiving, particularly the support they received through networks formed at Women's Refuge (Refuge). Women's reflections on their situations were examined, including reflections on the relationship itself; their experiences since the relationship had ended; the availability of information surrounding IPV; and how they framed their experiences. It was observed that the women depersonalised their former partners and were strong survivors, rather than passive victims. Many other studies on violence against women report similar findings to these, suggesting that 
there is a high level of consistency between the findings of this thesis and the wider literature.

\section{Overall Findings}

Up to this point the data has been generally presented in three discrete categories, suggesting that there is limited overlap between them. However, this is not the case. The following section seeks to draw the three categories of analysis together to create an overarching theory. The participants in this study clearly identified behaviours that women who experience IPV find supportive from their family and friends. To start with, families and friends should be encouraged to reach out to women when they suspect that there is something going on. This will remove the barrier of silence and make it more difficult for the women to hide the abuse. Furthermore, if women approach their family and friends for support, it is important that those they disclose to offer support. A number of the women in this study found that the people they disclosed to withdrew from them, which made their situations more difficult. Such reactions should be avoided where possible. When talking to women who have experienced IPV, family and friends should be encouraged to listen in a non-judgemental manner; help them to understand the dynamics involved in IPV; accept all decisions they make; and provide tangible assistance if possible. This would give the women the opportunity to vent, while giving them a greater understanding of their situation and a sense of strength.

These findings, however, should be regarded with caution, due to the limited nature of the sample. In particular, it should be noted that this was a strongly Pākehā sample and, as such, did not account for perspectives of a number of other New Zealand cultures, especially Māori. Metzger and Woodley (2010) state that culturally specific responses are vitally important, with many Māori reporting that their experiences are more positive when interventions are centred around, and led by, their family and community. This suggests that Māori women who experience IPV may find that 
assistance led by their wider family and community, and embedded in tikanga, ${ }^{15}$ may better meet their needs for support.

While it is clear that there are a number of ways of effectively providing support to women who experience IPV, the women in this study all had a number of negative experiences. In order to explain this, I will argue that there are two major forms of unsatisfactory support offered by family and friends, each with different causes: passive and active.

\section{Passive reactions}

Passive negative reactions come about through a lack of understanding of IPV. This partially stems from the stereotypes and attitudes mentioned in the Social Factors chapter. There is a perception that IPV is confined purely to physical acts, and mainly occurs between lower-income Māori or Pasifika couples. Furthermore, there is a belief that women should leave as soon as they first experience physical violence and, therefore, if they stay they are weak and stupid. The women in this study did not conform to these stereotypes and, as such, they did not realise that they were experiencing IPV. Additionally, because they did not understand the dynamics involved in IPV, they believed that they would be able to change their partners' behaviour. Both of these internal factors prevented participants from disclosing for a significant period of time. This lack of understanding about IPV also caused many family and friends to act in unhelpful ways. Many people gave advice and made comments based on this lack of understanding. Others judged, blamed or disbelieved them, based on the women's personal characteristics. Most people avoided the subject, and remained silent until the women brought it up themselves. These types of reactions served to keep the violence hidden and made it much more difficult for the women to disclose, leave the relationship and progress to a healthy life.

${ }^{15}$ Tikanga is a Māori word which refers to specific cultural customs, conventions and rules. 
The women believed that the biggest cause of this lack of understanding was a shortage of available information about IPV. They found that they had to go to a lot of effort in order to find out what resources were available to them, and to get any information about the dynamics and processes involved with IPV. By the time the women did this, they had already gone some way to figuring out what they had been experiencing, but they felt that they could have done with this information much sooner. Many of the participants believed that the best way to assist with greater understanding of IPV would be to implement relationship education in secondary schools. This education could provide young people with a greater understanding of what is healthy within a relationship and what is not, as well as examining the dynamics involved in abusive relationships. This would make it easier for those within a relationship to understand how they should treat each other, as well as enabling those on the outside of a relationship to recognise signs of IPV. Furthermore, this education should help people to understand what can be done when someone is in an abusive relationship. This would help those experiencing IPV to find resources available to them, while also informing their family and friends how best to help them. The need to make information on IPV more readily available, in particular through education, is not something that is confined to this study, being supported by a wide range of research (Black, 2011; Fanslow \& Robinson, 2010; Fugate, et al., 2005; Giles, et al., 2005; McDermott \& Garofalo, 2004; McLaren, 2010; Ministry of Social Development, 2002; Taylor \& Sorenson, 2005).

In addition to this need for education, two of the women identified dissatisfaction with current public awareness campaigns. One woman spoke about the fact that she did not feel that the current 'It's Not OK' campaign was representative of women in her position. Another woman stated that this campaign focused on stereotypical victims of IPV, while not effectively explaining what IPV actually is. As the Ministry of Social Development (2002, p. 11 \& 14) states, the objectives of the 'It's Not OK' campaign include preventing "family violence from occurring in the first place by 
raising public awareness" and increasing "public awareness and understanding of the nature, causes and effects of various forms and types of violence in families/whānau" (See also: Campaign for Action on Family Violence, et al., 2011; Giles, et al., 2005; McLaren, 2010). However, by over-representing women who conform to societal stereotypes, while not effectively defining IPV, this campaign is not achieving these objectives. This research suggests that the scope of the campaign be widened, in order to emphasise the points that IPV can happen to anyone, regardless of ethnicity or socio-economic background, and that IPV is not purely limited to physical acts.

\section{Active reactions}

Active negative reactions involve family and friends being unsupportive as the result of a conscious decision. This was most common in their family and friends' decisions to not help the women because they were staying in the relationship rather than being perceived to take action. This is consistent with findings that friends and family expect that women will leave if there is any violence, and get frustrated with them if they do not (Davis \& Brickman, 1996; Lempert, 1997). While this may be related to the lack of understanding described under 'passive reactions', and thus could be partially prevented by the suggestions listed above, this sort of reaction is more of a considered decision to withdraw support than those mentioned above.

Two of the women experienced active unsupportive reactions when the people they disclosed to had extensive experience with violence in their own lives. In both instances they were ignored, and the violence was concealed further. This can be explained by studies which find that those growing up in violent households are more likely to hold violence-supportive attitudes and, therefore, are less likely to support those who are experiencing violence (Flood \& Pease, 2009; Markowitz, 2001). The participants noted that many people do not want to examine their own circumstances and address their 
own problems. Instead, it is easier to ignore the problem and not take any action. The most effective way to reduce the incidence of this problem would be to reduce the incidence of family violence. According to the Ministry of Social Development (2002), the public awareness created by the 'It's Not OK' campaign, in conjunction with widespread education, has the ability to change societal norms and attitudes in relation to family. This would create a reduction in the prevalence of IPV in New Zealand. Despite the clear difference in causes, the suggestions outlined in 'passive reactions' above are likely to also have an impact on this type of active reaction, albeit over a longer time period.

\section{Research implications}

Throughout this research, the words of the women who were interviewed have been used, in order to give them a voice and draw attention to their experiences. In this sense, this research used a feminist perspective. However, as mentioned in chapter two, concerns are often voiced around male perspectives ignoring some of the important dynamics involved in feminist issues, particularly with regard to sensitive topics such as IPV (Harding, 1993; Letherby, 2003). This could call into question the appropriateness of a male researcher, such as myself, undertaking research in this area. But a number of authors argue that it is important for men to contribute to research on issues which have a negative impact on women, as long as they use a gendered lens and remain respectful of women's experiences and voices (Bathrick, Douglas, El, Perry, \& White, 2005; Harding, 1993). Because of the structural issues underlying violence against women, it is argued that significant progress will be harder to achieve unless men also engage with the issue and take a strong stand against it (Bathrick, et al., 2005; International Centre for Research on Women, 2012; White Ribbon Campaign, n.d.). Furthermore, men researching violence against women have the potential to bring new perspectives to the area. In line with the perspective, mentioned in chapter two, that marginalised populations provide a more complete analysis of the social world (Harding, 1993), 
Bathrick et al. (2005) argues that women have a higher level of consciousness about IPV. As such, it is possible that men, without this level of consciousness, have the potential to interpret information regarding IPV from a different perspective.

The literature referred to throughout this thesis included studies on both sexual violence and IPV, due to the similarities between the two areas. An example of these similarities can be seen in Kingi and Jordan's (2009) research, which finds that many women who experience sexual violence report non-judgemental listening and assistance in understanding their situation as positive support. These were also key findings for the women who experienced IPV in this study. Furthermore, both studies have found that victim-blaming is a common negative reaction to women who experience violence. Because of these similarities, it is suggested that secondary school education programmes and public awareness initiatives also be implemented to deal with sexual violence, where it is possible to do so in a sensitive manner.

This research used a grounded theory methodology with a small selfselected sample and, as such, the results cannot be generalised to the whole population. For this reason, it is suggested that further research be carried out in order to explore the findings of this study in greater detail. In particular, future research should test the value of non-judgemental listening; understanding; supporting decisions; and tangible support to women who experience violence. Furthermore, future research should test the cross-cultural validity of such findings, and investigate any support systems that may be more appropriate for non-Pākehā cultures within New Zealand. Additionally, further research should be carried out in order to examine the need for education and public awareness campaigns, and the directions that these initiatives need to take. In hypothesising a distinction between passive and active unsupportive reactions received by women who have experienced IPV, I have formulated a new theoretical framework to be 
used in researching violence against women. Future research is able to use this framework as a theoretical starting point, with the potential to test its validity and develop it further.

\section{Concluding Remarks}

For this thesis I interviewed six women who had been in violent relationships about their experiences in disclosing the abuse to family and friends. This began by examining the actions they took; the personal barriers to disclosure; and their reasons for disclosure. This was followed by an examination of the social factors influencing disclosure, including social barriers to disclosure; the negative reactions they received; and the positive reactions they received, alongside the effects of these reactions. This analysis then examined the ongoing support the women were receiving; the reflections they had on their situations; and the observations that I made of the women.

In concluding, it was argued that women who are experiencing IPV need their family and friends to reach out to them and listen to them nonjudgementally; help them to understand their situation; support their decisions; and provide appropriate tangible assistance. Furthermore, it was hypothesised that the problematic reactions encountered by women experiencing IPV can be divided into two types - passive and active. It was argued that passive reactions come about through a lack of understanding of IPV, whereas active reactions come about through a conscious decision not to provide assistance. In order to reduce the problems these women encountered it was suggested that secondary schools introduce widespread relationship education which examines what is and is not healthy in a relationship, and provides advice on how to assist someone in an unhealthy relationship. Additionally, it was argued that a more widespread public awareness campaign be run with a greater focus on the dynamics involved in IPV and less focus on stereotypes. These initiatives would assist in challenging and, potentially, changing societal norms and attitudes 
surrounding violence against women, creating an environment in which it is easier for women to disclose their experiences, thus breaking the silence that surrounds intimate partner violence. 


\section{References}

Allen, M. (2011). Violence and voice: Using a feminist constructivist grounded theory to explore women's resistance to abuse. Qualitative Research, 11(1), 23-45.

Aubrey, M., \& Ewing, C. P. (1989). Student and voter subjects: Differences in attitudes toward battered women. Journal of Interpersonal Violence, 4(3), 289-297.

Bachman, R., \& Schutt, R. K. (2012). Fudamentals of research in criminology and criminal justice (2nd ed.). Los Angeles, CA: Sage Publications, Inc.

Bancroft, J., \& Silverman, J. G. (2002). The batterer as parent: Addressing the impact of domestic violence on family dynamics. Thousand Oaks, CA: Sage Publications Inc.

Bathrick, D., Douglas, U., El, K. S., Perry, P. A., \& White, M. S. (2005). Organizing to end violence against women: Putting principles into practice. Decatur, GA: Men Stopping Violence.

Black, M. C. (2011). Intimate partner violence and adverse health consequences: Implications for clinicians. American Journal of Lifestyle Medicine, 5(5), 428-439.

Bui, H. N. (2003). Help-seeking behaviour among abused immigrant women: A case of Vietnamese American women. Violence Against Women, 9(2), 207-239.

Campaign for Action on Family Violence, Family and Community Services, \& Ministry of Social Development. (2011). Creating change: For people working to prevent family violence in New Zealand. Wellington, New Zealand: Campaign for Action on Family Violence.

Carlson, B. E. (1997). A stress and coping approach to intervention with abused women. Family Relations, 46(3), 291-298.

Clements, C. M., \& Ogle, R. L. (2009). Does acknowledgment as an assault victim impact postassault psychological symptoms and coping? Journal of Interpersonal Violence, 24(10), 1595-1614. 
Davis, R. C., \& Brickman, E. (1996). Supportive and unsupportive aspects of the behavior of others toward victims of sexual and nonsexual assault. Journal of Interpersonal Violence, 11(2), 250-262.

Denzin, N. K. (1984). Toward a phenomenology of domestic, family violence. American Journal of Sociology, 90(3), 483-513.

Dichter, M. E., \& Rhodes, K. V. (2011). Intimate partner violence survivors' unmet social service needs. Journal of Social Service Research, 37(5), 481-489.

Diederichs, N. M. (2005). Fictional warriors: Real responses, emotion, mood, and cognition in 'Once Were Warriors'. Master of Arts, University of Colorado, Boulder, CO.

Domestic Abuse Intervention Programs. (2011). Wheel Gallery Retrieved 02/05/2012, from http://www.theduluthmodel.org/pdf/PowerandControl.pdf

Dutton, M. A., Hohnecker, L. C., Halle, P. M., \& Burghardt, K. J. (1994). Traumatic responses among battered women who kill. Journal of Traumatic Stress, 7(4), 549-564.

Fanslow, J. L., \& Robinson, E. (2004). Violence against women in New Zealand: Prevalence and health consequences. The New Zealand Medical Journal, 117(1206), 1173-1183.

Fanslow, J. L., Robinson, E., Crengle, S., \& Perese, L. (2010). Juxtaposing beliefs and reality: Prevalence rates of intimate partner violence and attitudes to violence and gender roles reported by New Zealand women. Violence Against Women, 16(7), 812-831.

Fanslow, J. L., \& Robinson, E. M. (2010). Help-seeking behaviours and reasons for help-seeking reported by a representative sample of women victims of intimate partner violence in New Zealand. Journal of Interpersonal Violence, 25(5), 929-951.

Ferraro, K. J., \& Johnson, J. M. (1983). How women experience battering: The process of victimisation. Social Problems, 30(3), 325-339. 
Fields, M. D. (2008). Getting beyond 'what did she do to provoke him?': Comments by a retired judge on the special issue on child custody and domestic violence. Violence Against Women, 14(1), 93-99.

Flood, M., \& Pease, B. (2009). Factors influencing attitudes to violence against women. Trauma, Violence and Abuse, 10(2), 125-142.

Fugate, M., Landis, L., Riordan, K., Naureckas, S., \& Engel, B. (2005). Barriers to domestic violence help seeking: Implications for intervention. Violence Against Women, 11(3), 290-310.

Garcia-Moreno, C., Jansen, H. A. F. M., Ellsberg, M., Heise, L., \& Watts, C. H. (2006). Prevalence of intimate partner violence: Findings from the WHO multi-country study on women's health and domestic violence. The Lancet, 368, 1260-1269.

Gerbert, B., Caspers, N., Milliken, N., Berlin, M., Bronstone, A., \& Moe, J. (2000). Interventions that help victims of domestic violence: A quantitative analysis of physicians' experiences. Journal of Family Practice, 49(10), 889-895.

Giles, J. R., Curreen, H. M., \& Adamson, C. E. (2005). The social sanctioning of partner abuse: Perpetuating the message that partner abuse is acceptable. Social Policy Journal of New Zealand, 26, 97116.

Glaser, B. G. (1978). Theoretical sensitivity: Advances in the methodology of grounded theory. Mill Valley, CA: Sociology Press.

Glaser, B. G. (1992). Basics of grounded theory analysis. Mill Valley, CA: Sociology Press.

Hagan, F. E. (2012). Essentials of research methods in criminal justice and criminology (3rd ed.). Boston, MA: Prentice Hall.

Hamby, S. L., \& Gray-Little, B. (2000). Labeling partner violence: When do victims differentiate among acts? Violence and Victims, 15(2), 173186.

Harding, S. (1993). Rethinking standpoint epistemology: What is 'strong objectivity'? In L. Alcoff \& E. Potter (Eds.), Feminist epistemologies (pp. 49-82). London, United Kingdom: Routledge. 
Hayden, A. (2010). Why rock the boat? Non-reporting of intimate partner violence. Doctor of Philosophy, Auckland University of Technology, Auckland, New Zealand.

Hillier, L., \& Foddy, M. (1993). The role of observer attitudes in judgements of blame in cases of wife assault. Sex Roles, 29(9/10), 629-644.

Howard, J. A. (1984). The 'normal' victim: The effects of gender stereotypes on reactions to victims. Social Psychology Quarterly, 47(3), 270281.

International Centre for Research on Women. (2012). Violence against women: Engaging men and boys Retrieved 17/05/2012, from http://www.icrw.org/what-we-do/engaging-men-boys

Johnson, I. M. (2007). Victims' perspectives of police response to domestic violence incidents. Journal of Criminal Justice, 35, 498-510.

Johnson, M. P. (1995). Patriarchal terrorism and common couple violence: Two forms of violence against women. Journal of Marriage and Family, 57(2), 283-294.

Kaniasty, K., \& Norris, F. H. (1992). Social support and victims of crime: Matching event, support and outcome. American Journal of Community Psychology, 20(2), 211-241.

Kaukinen, C. (2002a). The help-seeking decisions of violent crime victims: An examination of the direct and conditional effects of gender and the victim-offender relationship. Journal of Interpersonal Violence, 17(4), 432-456.

Kaukinen, C. (2002b). The help-seeking of women violent crime victims: Findings from the Canadian violence against women survey. The International Journal of Sociology and Social Policy, 22(7/8), 5-34.

Kaukinen, C. (2004). The help-seeking strategies of female violent-crime victims: The direct and conditional effects of race and the victimoffender relationship. Journal of Interpersonal Violence, 19(9), 967990. 
Kearney, M. H. (2001). Enduring love: A grounded formal theory of women's experience of domestic violence. Research in Nursing and Health, 24, 270-282.

Kingi, V., \& Jordan, J. (2009). Responding to sexual violence: Pathways to recovery. Wellington, New Zealand: Crime and Justice Research Centre; Ministry of Women's Affairs.

Kristiansen, C. M., \& Giullieti, R. (1990). Perceptions of wife abuse: Effects of gender, attitude toward women, and just-world beliefs among college students. Psychology of Women Quarterly, 14, 177189.

Lamb, S. (1999). Constructing the victim: Popular images and lasting labels. In S. Lamb (Ed.), New versions of victims: Feminists struggle with the concept (pp. 108-138). New York, NY: New York University Press.

Langford, D. R. (2000). Developing a safety protocol in qualitative research involving battered women. Qualitative Health Research, 10(1), 133142.

Larcombe, W. (2002). The 'ideal' victim v successful rape complainants: Not what you might expect. Feminist Legal Studies, 10, 131-148.

Latta, R. E., \& Goodman, L. A. (2011). Intervening in partner violence against women: A grounded theory exploration of informal network members' experiences. The Counseling Psychologist, 39(7), 9731023.

Leibrich, J., Paulin, J., \& Ransom, R. (1995). Hitting home: Men speak about abuse of women partners. Wellington, New Zealand: Depatment of Justice.

Leisenring, A. (2006). Confronting 'victim' discourses: The identity work of battered women. Symbolic Interaction, 29(3), 307-330.

Lempert, L. B. (1997). The other side of help: Negative effects in the helpseeking processes of abused women. Qualitative Sociology, 20(2), 289-309. 
Letherby, G. (2003). Feminist research in theory and practice. Buckingham, United Kingdom: Open University Press.

Mahlstedt, D., \& Keeny, L. (1993). Female survivors of dating violence and their social networks. Feminism \& Psychology, 3(3), 319-333.

Markowitz, F. E. (2001). Attitudes and family violence: Linking intergenerational and cultural theories. Journal of Family Violence, 16(2), 205-218.

McDermott, M. J., \& Garofalo, J. (2004). When advocacy for domestic violence victims backfires: Types and sources of victim disempowerment. Violence Against Women, 10(11), 1245-1266.

McLaren, F. (2010). Attitudes, values and beliefs about violence within families: 2008 survey findings. Wellington, New Zealand: Centre for Social Research and Evaluation.

McManus, J. (2005). Functional truth or sexist distortion? Assessing a feminist critique of intimate violence reporting. Journalism, 6(1), 43-65.

McPhail, B. A., Busch, N. B., Kulkarni, S., \& Rice, G. (2007). An integrative feminist model: The evolving feminist perspective on intimate partner violence. Violence Against Women, 13(8), 817-841.

Metzger, N., \& Woodley, A. (2010). Report on giving, receiving and seeking help: The campaign for action on family violence. Retrieved June 1st, 2011, from http://www.msd.govt.nz/documents/about-msdand-our-work/publications-resources/research/campaign-actionviolence-research/report-on-giving-receiving-and-seeking-help.pdf

Ministry of Social Development. (2002). Te Rito: New Zealand family violence prevention strategy. Wellington, New Zealand: Ministry of Social Development.

Moe, A. M. (2007). Silenced voices and structured survival: Battered women's help seeking. Violence Against Women, 13(7), 676-699.

Nayak, M. B., Byrne, C. A., Martin, M. K., \& Abraham, A. G. (2003). Attitudes toward violence against women: A cross-nation study. Sex Roles, 49(7/8), 333-342. 
Pavlou, M., \& Knowles, A. (2001). Domestic violence: Attibutions, recommended punishments and reporting behaviour related to victim provocation. Psychiatry, Psychology and Law, 8(1), 76-85.

Postmus, J. L., Severson, M., Berry, M., \& Ah Yoo, J. (2009). Women's experiences of violence and seeking help. Violence Against Women, 15(7), 852-868.

Reynolds, J., \& Wetherell, M. (2003). The discursive climate of singleness: The consequences for women's negotiation of a single identity. Feminism \& Psychology, 13(4), 489-510.

Romito, P. (2008). A deafening silence: Hidden violence against women and children. Bristol, United Kingdom: The Policy Press.

Rusbult, C. E., \& Martz, J. M. (1995). Remaining in an abusive relationship: An investment model analysis of nonvoluntary dependence. Personality and Social Psychology Bulletin, 21(6), 558-571.

Seecombe, K., James, D., \& Walters, K. B. (1998). "They think you ain't much of nothing": The social construction of welfare mother. Journal of Marriage and Family, 60(4), 849-865.

Skelton, C. A., \& Burkhart, B. R. (1980). Sexual assault: Determinants of victim disclosure. Criminal Justice and Behavior, 7(2), 229-236.

Snowden, L. R. (1998). Racial differences in informal help seeking for mental health problems. Journal of Community Psychology, 26(5), 429-438.

Strube, M. J., \& Barbour, L. S. (1983). The decision to leave an abusive relationship: Economic dependence and psychological commitment. Journal of Marriage and Family, 45(4), 785-793.

Sudderth, L. K., Leisring, P. A., \& Bronson, E. F. (2009). If they don't tell us, it never happened: Discloure of experiences of intimate partner violence on a college campus. Canadian Women Studies, 28(1), 5664.

Sullivan, C. M., Basta, J., Tan, C., \& Davidson, W. S. (1992). After the crisis: A needs assessment of women leaving a domestic violence shelter. Violence and Victims, 7(3), 267-275. 
Sullivan, C. M., \& Cain, D. (2004). Ethical and safety considerations when obtaining information from or about battered women for research purposes. Journal of Interpersonal Violence, 19(5), 603-618.

Taylor, C. A., \& Sorenson, S. B. (2005). Community-based norms about intimate partner violence: Putting attributions of fault and responsibility into context. Sex Roles, 53(7-8), 573-589.

The Sophie Elliott Foundation. (n.d.). Sophie's story Retrieved 02/05/2012, from http://www.sophieelliottfoundation.co.nz/Sophies_Story.php

Towns, A. J., \& Adams, P. J. (2009). Staying quiet or getting out: Some ideological dilemmas faced by women who experience violence from male partners. British Journal of Social Psychology, 48, 735754.

Van Hook, M. P. (2000). Help seeking for violence: Views of survivors. Affilia, 15(3), 390-408.

Waldrop, A. E., \& Resick, P. A. (2004). Coping among adult female victims of domestic violence. Journal of Family Violence, 19(5), 291-302.

West, A., \& Wandrei, M. L. (2002). Intimate partner violence: A model for predicting interventions by informal helpers. Journal of Interpersonal Violence, 17(9), 972-986.

White Ribbon Campaign. (n.d.). Key messages of the White Ribbon Campaign $\quad$ Retrieved 30/04/2012, from http://whiteribbon.org.nz/about/key-messages/

Witte, T. H., Schroeder, D. A., \& Lohr, J. M. (2006). Blame for intimate partner violence: An attributional analysis. Journal of Social and Clinical Psychology, 25(6), 647-667.

Yeboah, D. A. (2008). Research methodologies in criminology. New York, NY: Nova Science Publishers, Inc.

Zimbardo, P. (2007). The Lucifer effect: How good people turn evil. London, United Kingdom: Rider Books. 


\section{Appendix A: Ethics Approval}

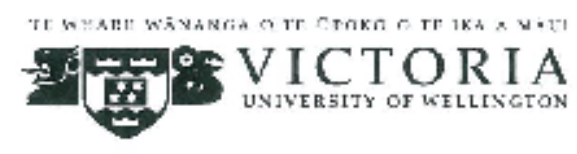

MEMORANDUM

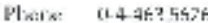

Tax a-110:35na

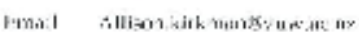

\begin{tabular}{|c|c|}
\hline TO & Járed Walun \\
\hline COPY TO & D. Venesia Kirgi. Monica Lichti \\
\hline FROBA & Ur Alison Kirkmen, Comvener, Hurran Ethics Commitee \\
\hline DATE & 1 July 2011 \\
\hline PAGFS & 1 \\
\hline
\end{tabular}

SUR.JEGT Ethics Approval: 18651 - Intimate Partner Violence: An investigation into victims' treatment by family and friends in New Zealand.

Thank you for your application for ethical aporowal, which has now beer oongidered by t'ie Sconol of Social and Cultural Stldies Human Fthics Sulb-Commillee under de egated authority from :he Vic:orla University Human Ethics Committee.

Your upplicution hes becn aporoved from the abave date and this aproval continues unlil 30 may 20\%2. If your data collection is ro: on pleted by this datc you should apply to the Human Ethics Comm thee fur an exicersion to this approval.

Best wishes with the research

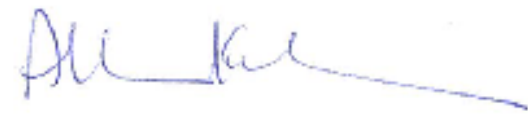

All

Convener 


\title{
Appendix B: Informant Information Sheet and Consent Form
}

\author{
VICTORIA UNIVERSITY OF WELLINGTON \\ Te Whare Wānanga o te Ūpoko o te Ika a Māui

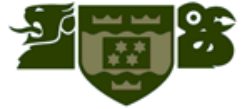

\section{Intimate Partner Violence: An Investigation into Victims’ Treatment by Family and Friends in New Zealand \\ Information Sheet - Informant}

I am a Master of Arts student carrying out a study on how victims of intimate partner violence in New Zealand feel they have been treated by their family and friends. The findings from this study will be presented in a thesis which will then be submitted for marking to the School of Social and Cultural Studies at Victoria University of Wellington. This project has gained approval from Victoria University of Wellington Human Ethics Committee.

\section{Invitation}

I am inviting people who work with survivors of intimate partner violence to take part in some key informant interviews, in order to help me develop my research focus prior to interviewing participants.

Taking part in this research will involve talking to me for about an hour about your experiences working with survivors of intimate partner violence and how these could be applied to my research. I will be asking questions such as:

- What is your experience in working with victims of intimate partner violence?

- In your experience, what is the best way to approach research with survivors of intimate partner violence?

- Do you have any advice on how I can make the participants more comfortable with the fact I am male?

Participation is completely voluntary and you can withdraw from the study at any point prior to October 2011 with no explanation required. With your permission these interviews will be tape recorded and later transcribed.

\section{Confidentiality}

I will keep everything that you tell me confidential, and only use this for the expressed purposes of this study. Your name and all other identifying factors will not be used in my thesis.

\section{Participation}

Should you chose to participate in this research, you can request to view your interview transcript and/or receive a summary of the final report. If you have any questions regarding this research, or would like to participate, please contact myself or my supervisor Dr Venezia Kingi using the details below.

Thank you in advance for your time

Jared Walton

Master of Arts Candidate

Victoria University of Wellington

jared.walton@vuw.ac.nz

0274034770
Dr Venezia Kingi

Crime and Justice Research Centre Victoria University of Wellington venezia.kingi@vuw.ac.nz 044635874 


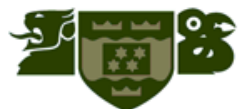

\section{Intimate Partner Violence: An Investigation into Victims' Treatment by Family and Friends in New Zealand \\ Consent Form - Informant}

I have been provided with an information sheet and have had the purpose of the research explained to me by the researcher.

I am aware that I can pull out of this research at any point before October 2011 without being required to provide a reason.

I understand that all information that I provide will remain confidential and will only be used for the purposes of this study.

I understand that my name and all other identifying factors will be removed from all research reports.

I agree for my interview to be taped.

I agree for my interview to be transcribed by the interviewer, or a professional transcriber.

I would like a copy of my interview transcript.

I

(full name)

hereby consent to take part in this study.

Date: 120

Signature:

Email address: 


\section{Appendix C: Informant Interview Guide Interview Guide - Informant}

[Interviewee will be given a summary of my research and the questions I plan to ask participants]

What is your experience in working with survivors of intimate partner violence?

In your experience, what is the best way to approach research with victims of intimate partner violence?

- What is the best way to handle questioning participants on such sensitive subject matter?

- Would you make any changes to the questions I intend to ask participants or the way in which these questions are worded?

Do you have any advice on how I can make the participants more comfortable with the fact I am a male researcher?

- What is the best way to avoid perpetuating gender inequalities?

- What is the best way to avoid worsening ongoing emotional issues?

Do you have any other advice for how I should go about conducting this research? 


\title{
Appendix D: Participant Information Sheet and Consent Form
}

\author{
VICTORIA UNIVERSITY OF WELLINGTON \\ Te Whare Wānanga o te Ūpoko o te Ika a Māui

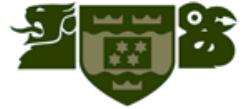

Intimate Partner Violence: An Investigation into Survivors’ Treatment by Family and Friends in New Zealand

\section{Information Sheet - Participant}

I am a Master of Arts student carrying out a study on how survivors of intimate partner violence in New Zealand feel they have been treated by their family and friends. The findings from this study will be presented in a thesis which will then be submitted for marking to the School of Social and Cultural Studies at Victoria University of Wellington. This project has gained approval from Victoria University of Wellington Human Ethics Committee.

\section{Invitation}

I am inviting survivors of intimate partner violence to participate in this study. You need to:

- $\quad$ Be female

- $\quad$ Be aged 18 years or older

- Have been a victim of intimate partner violence within the past 5 years

- $\quad$ No longer be in the violent relationship

If you are not sure if you meet these criteria you can discuss this with the researcher.

Taking part in this research will involve meeting with the researcher for about an hour to discuss your experiences with intimate partner violence. I will be asking questions such as:

- $\quad$ Did you receive the support you were seeking in telling family and friends about the violence?

- What things were helpful and what things were not?

- $\quad$ Did the way the people you told treated you change (whether positively or negatively) after you told them?

Participation is completely voluntary and you can withdraw from the study at any point prior to December 2011 with no explanation required. With your permission these interviews will be tape recorded and later transcribed. You are free to bring with you a friend, family or whānau member to support you if you would like. As I am a male, I am willing to have a female colleague present for the interview if you would like me to.

\section{Confidentiality}

I will keep everything that you tell me confidential, and only use this for the expressed purposes of this study. Your name and all other identifying factors will not be used in my thesis. If, for any reason, I feel that you or anyone else is at serious risk of harm I may break confidentiality. However, I will discuss this with you beforehand if such a situation arises.

\section{Participation}

Should you chose to participate in this research, you can request to view your interview transcript and/or receive a summary of the final report. If you have any questions regarding this research, or would like to participate, please contact myself or my supervisor Dr Venezia Kingi using the details below.

Thank you in advance for your time

Jared Walton

Master of Arts Candidate

Victoria University of Wellington

jared.walton@vuw.ac.nz

0274034770
Dr Venezia Kingi

Crime and Justice Research Centre

Victoria University of Wellington venezia.kingi@vuw.ac.nz

044635874 


\section{VICTORIA UNIVERSITY OF WELLINGTON}

Te Whare Wānanga o te Ūpoko o te Ika a Māui

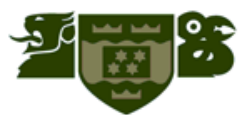

\section{Intimate Partner Violence: An Investigation into Survivors' Treatment by Family and Friends in New Zealand}

\section{Consent Form - Participant}

I have been provided with an information sheet and have had the purpose of the research explained to me by the researcher.

I am aware that the researcher is a male and that if this makes me feel uncomfortable I can request that the researcher have a female colleague present with them throughout the interview.

I am aware that I can pull out of this research at any point before December 2011 without being required to provide a reason.

I understand that all information that I provide will remain confidential and will only be used for the purposes of this study.

I understand that my name and all other identifying factors will be removed from all research reports.

I understand that I am entitled to have a friend, family or whānau member present for emotional support.

I understand that if the researcher believes that I, or anyone else, is in danger he may break confidentiality. However, this will be discussed with me beforehand.

I agree for my interview to be taped.

I agree for my interview to be transcribed by the interviewer, or a professional transcriber.

I would like a copy of my interview transcript.

I

(full name)

hereby consent to take part in this study.

Date: 120

Signature:

Email address: 


\section{Appendix E: Participant Interview Guides}

\section{Participant Interview Guide - Annette}

Did you tell your family and friends about your experience? If so, why?

- Why them and not others?

How did you feel the people you told treated you?

- Did they provide the support you were seeking?

- What actions were helpful and what actions weren't?

- Did their attitude towards you seem to change?

- Do you feel that other people's attitudes towards you changed?

- Did you feel judged or stigmatised?

- How did this influence your actions [e.g. leaving the relationship, calling the Police etc.]?

How has your treatment affected the way you would react if you were to experience IPV in the future?

Are there any other comments you would like to add? 


\section{Participant Interview Guide - Bianca, Chloe and Dani}

Did you tell your family or friends about your experience?

- At what point did you disclose [e.g. during or after the relationship]?

0 Why then and not at other points?

0 Were there any barriers to disclosing?

o Did you try and hide it? If so, did people make that easy [e.g. accepting farfetched explanations for injuries]?

- How many people did you disclose to? What influenced your decision to tell them in particular?

- Are there any demographic factors that influenced these decisions [esp. culture and age]?

- If someone asked you about it, would the outcome have been difference?

- In future would you disclose at a different stage or to different people?

What were you looking for in disclosing [e.g. solutions or just to get it out]?

- Did you receive that?

- Were there any effects of disclosure that you didn't expect? How so?

- Did you feel supported?

o Do you feel this support is ongoing?

- Were some people more helpful than others? How so?

o Was there a pattern to this [e.g. his friends weren't helpful]?

- Did you feel judged or stigmatised?

- Did you feel that people treated you any differently (both those you told and those you didn't)?

- Did your disclosure cause you to take any further actions [e.g. involving the CJS]?

o If not, do you think you would have if someone had pushed it?

- Did you feel any stereotypes were forced upon you [e.g. of victimhood]?

Are there any other comments you would like to add? 


\section{Participant Interview Guide - Erica and Frances}

Did you tell your family or friends about your experience?

- At what point did you disclose [e.g. during or after the relationship]?

- How many people did you disclose to? What influenced your decision to tell them in particular?

- Are there any demographic factors that influenced these decisions [esp. culture and age]?

- Were there any barriers to disclosure?

- When you did tell people did you receive a positive reaction?

o What actions were helpful?

o What actions weren't helpful?

- Do you have ongoing support?

- Have there been any major realisations/reflections you've had since the relationship?

- Stigma

- Stereotypes

- Privacy

- Aims of disclosure

Are there any other comments you would like to add? 